MANnheim Research Institute for the ECONomics of Aging

UNDERSTANDING THE TRENDS IN INCOME, CONSUMPTION, AND WEALTH INEQUALITY AND HOW IMPORTANT ARE LIFE-CYCLE EFFECTS?

Mathias Sommer

$160-2008$

○ $\boldsymbol{m e a - M a n n h e i m ~ R e s e a r c h ~ I n s t i t u t e ~ f o r ~ t h e ~ E c o n o m i c s ~ o f ~ A g i n g ~}$

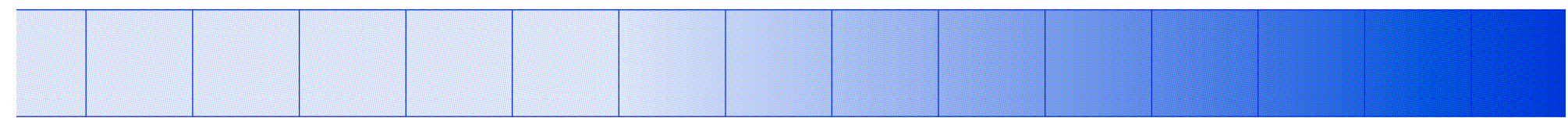

L13, 17_D-68131 Mannheim_Phone +49 621 181-2773/1862_Fax +49 621 181-1863_www.mea.uni-mannheim.de 


\title{
Understanding the trends in income, consumption and wealth inequality and how important are life-cycle effects?
}

\author{
Mathias Sommer ${ }^{\dagger}$
}

This version: July 2008

\begin{abstract}
Rising inequality in income, wealth and consumption has received a good deal of public attention in the past years. At the same time, also macroeconomists are more and more interested in inequality as they have expanded their models to incorporate heterogeneity in the household sector. We supply these models with empirical benchmarks for their calibration and contribute to the understanding of the reasons underlying the trends in inequality. Specifically, we employ a variance decomposition and estimate life-cycle profiles of inequality in income, consumption and wealth based on two measures of inequality. We deepen the discussion on wealth inequality by evaluating the relative importance of savings, portfolio choice and inheritances for the accumulation of wealth. To do so, we project active and passive savings based on the observed saving and investment behavior of synthetic cohorts from the German Income and Expenditure Survey (EVS).
\end{abstract}

Keywords: inequality, income, consumption, wealth, savings, portfolio choice, bequests.

\footnotetext{
* We thank Dirk Krüger, Nicola Fuchs-Schündeln, Axel Börsch-Supan, Anette Reil-Held, and Tilman Eichstädt for their helpful comments and suggestions. We are grateful for financial support from the Gesamtverband der Versicherungswirtschaft, the state of Baden-Württemberg and the German Research Foundation (DFG). Finally, we thank Esther Steinmetz for her research assistance.
}

† MEA - Universität Mannheim; Email: sommer@econ.uni-mannheim.de 


\section{Introduction}

The term inequality seems to have a purely negative connotation when we look at the public debate about rising inequality. Especially in continental Europe, there is a vigorous public and political debate about the need and possible ways to mitigate the effects which are largely ascribed to globalization. This debate is only to a minor degree based on scientific results despite that fact that there is a substantial literature on inequality that reaches back into the 1960s. However, the sources of rising inequality are still not very well understood. Further, natural components in the observed trends, which may e.g. be induced by changes in the population structure, by the globalization, or by skill-biased technological change have received rather little attention so far.

At the same time macroeconomists have been largely ignorant to the matter of inequality in the past. Incorporating heterogeneity into their quantitative models has only recently become possible with the availability of sufficiently powerful computers. With the grown opportunities to refine the quantitative models there is a growing need for empirical benchmarks for the calibration of these models.

The purpose of this paper is twofold. First, we document the trends in income, consumption and wealth inequality in Germany over the past 25 years. While this has been done in the past e.g. by Becker and Hauser (2003), the goal of our work in collaboration with a large community of international researchers is to provide results for a variety of countries based on common definitions. ${ }^{1}$ We thereby aim to provide an empirical benchmark for future macroeconomic models. Given the popularity of OLG models for capturing the characteristics of aging economies, we put a special focus on the analysis of inequality in a life-cycle context.

Understanding the sources of rising inequality, however, seems especially important also for the assessment of the need for political action against rising inequality. We therefore compare the trends in inequality from the raw data to the remaining inequality after filtering out structural

\footnotetext{
${ }^{1}$ The results documented in this paper are closely comparable to our work for the joint project "cross-sectional facts for macroeconomists (CFM)". The project, initiated by Dirk Krüger, Fabrizio Perri, Luigi Pistaferri, and Gianluca Violante includes empirical work from 10 countries. In collaboration with Nicola Fuchs-Schündeln and Dirk Krüger we provide the German contribution to the project. The chapters four and five of this paper contain the EVS analyses which we also provide for the CFM-project, but without the sample restriction applied in the CFM project. Specifically, we restrict the sample for the CFM-project to households headed by a 25 to 60 year old. Accordingly, also the life-cycle analyses focus only this age-band. For our analysis, we extend the focus over all age-groups. Section six of this paper provides an independent analysis, which is not part of the CFM-project and based on joint interests with Tilman Eichstädt.
} 
changes in the population structure. Procedurally, we employ a variance decomposition to obtain trends in residual inequality. Similar exercises have been carried out e.g. by Schwarze (1996) who uses a Theil decomposition to assess the effects of the German reunification on the national trends in income inequality.

While a considerable literature has investigated possible drivers behind income inequality, deeper analyses of the backgrounds to wealth inequality are rare. Among the few exceptions are the analyses by Hendricks (2007) and Scholz (2003). Hendricks estimates discount rates from lifecycle wealth data and uses the estimated preference parameters to predict wealth inequality. $\mathrm{He}$ finds differences in discount rate heterogeneity to significantly improve the predictions of wealth inequality from life-cycle models except for the top of the wealth distribution. Overall, his results support the view that life-cycle savings can account for a large part of wealth inequality. Therefore, demographic changes may be among the drivers of wealth inequality. We concur with Scholz (2003) who argues that looking at changes in the cross-sectional distribution of wealth, we are unable to understand the evolution of household wealth and thus receive an inaccurate view on the evolution of wealth inequality. While Scholz focuses on a comparison of the wealth accumulation of the baby boom generation with their parents, our goal is a more general one. We aim to present a stylized pattern of wealth accumulation in a life-cycle context and assess the relative importance of active and passive savings as well as inheritances at different parts of the income distribution and different ages.

The paper is organized as follows. We start out in section two with conceptual considerations about economic inequality and deduce the variables and definitions employed in the subsequent analyses. Section three shortly describes the data we use for our analysis. Section four presents the aggregate trends in the levels of income, consumption and wealth and the respective trends in inequality. We then turn to the decomposition of inequality in section five. We start with a crosssectional perspective on the parts of inequality connected to observable household characteristics before we then turn to the life-cycle effects in inequality which. Section six is dedicated to our analysis of the different drivers behind wealth accumulation in a life-cycle context. Section seven concludes. 


\section{Conceptual considerations about inequality}

Focusing on economic measures of wellbeing we certainly disregard a variety of dimensions which might be important for comprehensive assessment of differential wellbeing in a society. Important examples are the value of health and of social networks. While the contribution of such non-financial factors to individual welfare is non-trivial to quantify, also the right measurement of economic inequality has received considerable attention the literature. Income, consumption and wealth have all been employed and depending on the research question at hand the choice of different variables is only well-founded.

We aim to provide a rather general survey of differential wellbeing in a life-cycle context and therefore present evidence on all three measures. Furthermore, all three could be employed for the evaluation of macroeconomic models. Before turning to the actual analyses, we shortly discuss the significance of income, consumption and wealth inequality with respect to individual welfare and introduce the data we use.

\section{II.1 Income}

The link between income and wellbeing is an indirect one. Given that economists usually consider wellbeing a synonym for utility and utility to be derived from consumption and leisure, income does not seem the measure of choice. At the same time income is rather easy to measure and can be interpreted as a measure of immediate consumption opportunities. The obvious income measure is therefore disposable (post-government) income, which we define as the sum of gross work and asset income plus private and public transfers net of taxes and contributions to the social security system. For an assessment of the redistributive effects of the government sector it might further be interesting to compare pre- and post-government income, as it is done by Schwarze (1996). In the literature, also analyses focusing on certain income components have received some attention. Especially research questions with respect to the labor market have investigated the distribution of gross work income and wages. Recent example for the case of Germany are Becker (2006) and Gernandt and Pfeiffer (2006). Both lines of research are beyond the purpose of this paper. ${ }^{2}$

\footnotetext{
2 In Fuchs-Schündeln et al. (2008) we focus on the working age population and provide comparative analyses of inequality in pre- and post-government income as well as work income and wages.
} 


\section{II.2 Consumption}

As mentioned above, income is not necessarily a good measure of actual wellbeing. Consumption smoothing over the life-cycle as first suggested by Modigliani and Brumberg (1954) as well as home production (Gronau, 1976) blur the link between income and consumption utility. Although consumption is much more directly linked to individual wellbeing, measuring inequality in consumption is not suited to thoroughly solve the problems. First, the issues around unaccounted utility from home production persist. Second, theory suggests that utility is not linear in consumption expenditures and may further depend on leisure. Third, consumption expenditures need not coincide with derived utility. This is especially the case for durable goods like cars or furniture. While it would conceptually be possible to distribute consumption utility of durable goods over their life-time, this is rarely done in practise. One of the main reasons is that most surveys lack information on the value of durable goods in the household. ${ }^{3}$ Further, household expenditures for durables tend to occur irregularly and infrequently. As a consequence, the usual time frame over which household consumption is recorded is too short to receive a comprehensive picture of durable consumption. ${ }^{4}$ For an assessment of consumption inequality it is therefore common practise to focus on non-durable consumption and we follow this approach. ${ }^{5}$

\section{II.3 Wealth}

Thinking about inequality in utility, analyses of wealth inequality seem out of place at the first thought. To the extent that wealth is ultimately used for consumption purposes, we should care about consumption inequality at the time of usage rather than about wealth itself. Given that we cannot measure future consumption, wealth may serve as a good proxy. Especially in the context of private old age provision, utility from wealth can be quantified, e.g. by converting projected net wealth at retirement into a lifelong annuity. An exact quantification would then depend largely on assumptions about certain probabilities, most importantly survival and changes to the household composition. In the subsequent analysis we assume that wealth will eventually be used

\footnotetext{
3 This also applies to the available household data in Germany and in our case the data from the German Income and Expenditure Survey (EVS). Specifically, the EVS contains only information on the number of selected durables, like cars, dishwashers, etc., but none about their value.

${ }^{4}$ For a discussion of the possible effects of the switch from an annual household diary to quarterly data in the EVS between 1993 and 1998 on consumption inequality see Sommer (2008).

5 The construction of a harmonized definition of non-durable consumption in the EVS is documented in Sommer (2008).
} 
for consumption in an unaltered household context. ${ }^{6}$ Furthermore we abstract from survival probabilities and thereby implicitly aim at the expected present discounted value of future consumption derived from a fair annuity. It is unclear, however, whether all wealth will actually be employed for retirement consumption or if it will be handed on - unused - to the next generation. As reverse mortgages remain to be rarely used to convert housing wealth into additional income, this argument seems especially applicable for real estate wealth. To account for the questionable use of housing wealth in this context, we present results for inequality in net financial wealth and net total wealth.

Based on the above procedure, we largely disregard utility which wealth may provide by its plain existence. In fact, wealth may facilitate access to the credit market and thereby generate opportunities. Furthermore, - through the above credit channel or by itself - wealth may facilitate consumption smoothing and thereby lead to higher lifetime utility. ${ }^{7}$ In practise, it is quite difficult to quantify the utility from these functions of wealth. We would have to make assumptions about the magnitude and the incidence of income fluctuations. Furthermore, different kinds of wealth are differently suitable to fill the various functions. Real estate wealth, for instance, is highly valued as a collateral for credit, yet it provides essentially no bufferstock function against income fluctuations. There is, however, a third channel through which wealth may provide utility. Specifically, wealth may take the form of consumer durables like in the case of an owner occupied dwelling. In this case, we measure the derived utility by including the rental value of the residence in income and consumption.

\footnotetext{
${ }^{6}$ An alternative assumption would be that only the adult household members will ultimately use the existing wealth for retirement consumption. This would imply the application of an equivalence scale which disregards children in the household. At the same time, financial support of the children, e.g. for their education, and inter-vivos transfers may be good reasons not to neglect the presence of children in the household.

7 The importance of wealth for consumption smoothing has been assessed by Carrol and Samwick (1998) who estimate the share of wealth accumulated for this purpose to attain up to 46 percent of total wealth.
} 


\section{Data}

Inequality analyses foremost require a sufficiently large dataset. Whereas means can reasonably well be estimated from a rather smaller sample, being interested also in the dispersion and the tails of a distribution implies much higher demands on the dataset. For our purpose of analyzing inequality in a life-cycle context, we would ideally employ a long series of panel data covering income, consumption and wealth. This would not only allow us to separate age- and cohorteffects but even provide the ground for mobility analyses.

Only two German data sets fulfill the requirements with respect to a sufficient sample size and a sufficient time series. A comparison of the German Socioeconomic Panel (GSOEP) and the German Income and Expenditure Survey (EVS) which have both been used for a variety of inequality analyses is provided by Becker et al. (2002). The German Socioeconomic Panel (GSOEP) reaches back to 1984 and offers a sample size of up to 12'000 households. Furthermore a high-income sample has been added in 2003 which enhances analyses with respect to the rich. Fuchs-Schündeln et al. (2008) employ the GSOEP for an analysis of income and wage inequality. Unfortunately, wealth has only become part of the questionnaire in recent years and consumption is untapped by the GSOEP. ${ }^{8}$

We therefore rely on the German Income and Expenditure Survey (EVS), which covers income, consumption and wealth even at slightly more detail. The sample size of roughly 40'000-60'000 households per year has predestined the German Income and Expenditure Survey (EVS) for inequality analyses already in the past (see e.g. Hauser and Stein (2001), Hauser (2003), Becker and Hauser (2003)). The main downside of the EVS is certainly that it consists of independent cross-sections rather than a panel. Of the EVS cross-sections, which started in 1962/63, we employ the available scientific use files from the years 1978 through 2003 for our analysis. The survey was implemented at five year intervals so that we have six cross-sections available. Comparability of the surveys over time has been a secondary concern for the Federal Statistical Office behind adding recent developments in consumption and income and improving the survey conceptually. A large deal of the implied issues can be dealt with by imputation and harmonization procedures which are documented in Sommer (2008). Sommer also discusses the effects of two important structural problems in the EVS: Specifically, the Federal Statistical

\footnotetext{
${ }^{8}$ Among the other German surveys especially the SAVE survey stands out with a comprehensive questionnaire on savings and wealth. Its sample size of roughly 2000 households and the still short panel dimension of 5 years between 2001 and 2007 are unsuitable for our purposes though.
} 
Office applies a sampling threshold which has been shown to limit the ability of the EVS to capture the top income households (Merz, 2003). It seems questionable though to what extent other German surveys are more successful in capturing the very top of the income distribution.' To compensate for the differences in the default thresholds over time, we apply an indexation to the threshold and disregard observations above the most constraining threshold which was applied in 1988. Overall, this leads to dropping 53 observations out of a total 267'434 in all six cross-sections. ${ }^{10}$ The second important structural change concerns the household diary which is employed for the collection of income and consumption data. To reduce the time and effort on behalf of the participating households, the diary was switched from an annual to a quarterly one between 1993 and 1998. We can expect the distributions of income and consumption to be affected by these changes. However, the dimensions of the consequences are hard to quantify and will likely differ strongly by the variable under scrutiny. Unfortunately, little can be done to correct for the possible bias in the distribution of projected annual measures. ${ }^{11}$ Instead, comparative analyses of the pre-1998 data with the more recent data should involve careful interpretation.

\footnotetext{
${ }^{9}$ Sommer (2008) shows that the GSOEP contains only a handful of households above this threshold even after the inclusion of the GSOEP-high-income sample. This indicates that there is simply not much hope of learning more about the very top of the German income distribution from the existing data.

10 A comparison of our correction procedure to a procedure proposed by Hauser (2006) is provided in Sommer (2008). In that paper, we also address the effects of the two correction procedures on the distribution of selected variables.

${ }^{11}$ We discuss the direction and size of the expected bias in Sommer (2008)
} 


\section{Trends in inequality in Germany}

Before we turn to the actual investigation of the determinants of inequality and with a special focus on inequality over the life-cycle we document the trends in the levels of income, consumption and wealth and describe the evolution of their dispersion over the last decades.

\section{IV.1 Trends in household income, consumption and wealth}

Income and consumption in Germany have grown at a slow but steady pace over most of the last 25 years. Based on the EVS data we estimate a compound annual growth rate of per capita nondurable consumption of 1.2 or 0.8 percent in real terms, depending on whether we include housing expenditures in non-durable consumption or not. ${ }^{12}$ Average disposable income per capita has grown at a similar rate of roughly 1 percent per year (see figure 1).

Figure 1: Trends in average per capita income and non-durable consumption

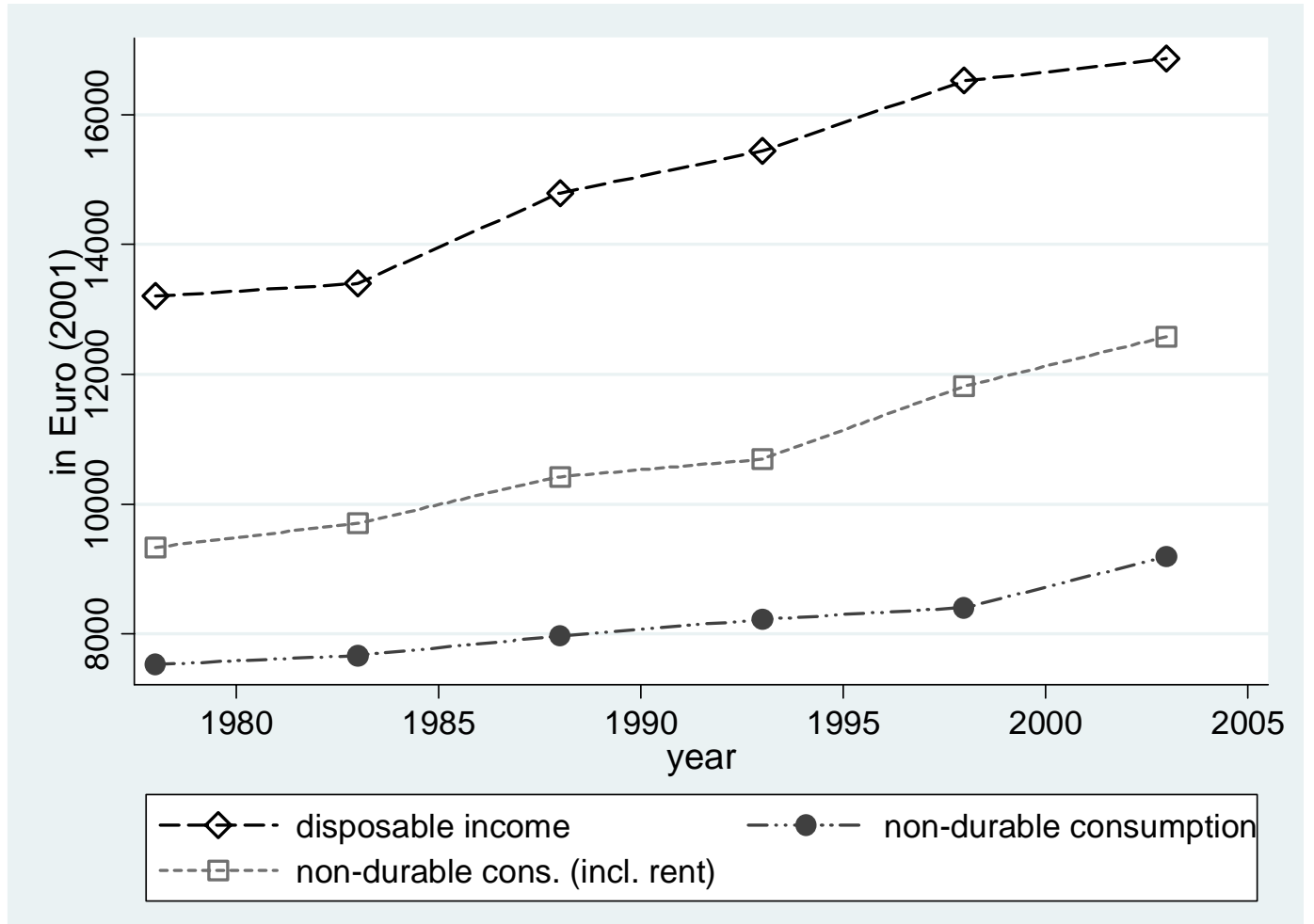

Source: own calculations based on the EVS 1978-2003

\footnotetext{
12 The definition of housing expenditures also includes hypothetical rent of owner occupiers. A full description of the expenditures included in our definition of non-durable consumption is given in Sommer (2008).
} 
Figure 2 displays how average per capita net financial and net total wealth have evolved over the last decades. The growth in financial wealth appears much less impressive at first sight, but starting from much lower levels financial wealth has actually seen higher compound annual growth rates. Specifically, financial wealth has grown by an average 2.5 percent per year, whereas total wealth has grown by only 2.07 percent, indicating the somewhat lower growth rates of net real wealth. As a consequence, the share of wealth in financial assets has grown by about 3 percentage points to roughly 31 percent in 2003.

Figure 2: Trends in per capita net wealth

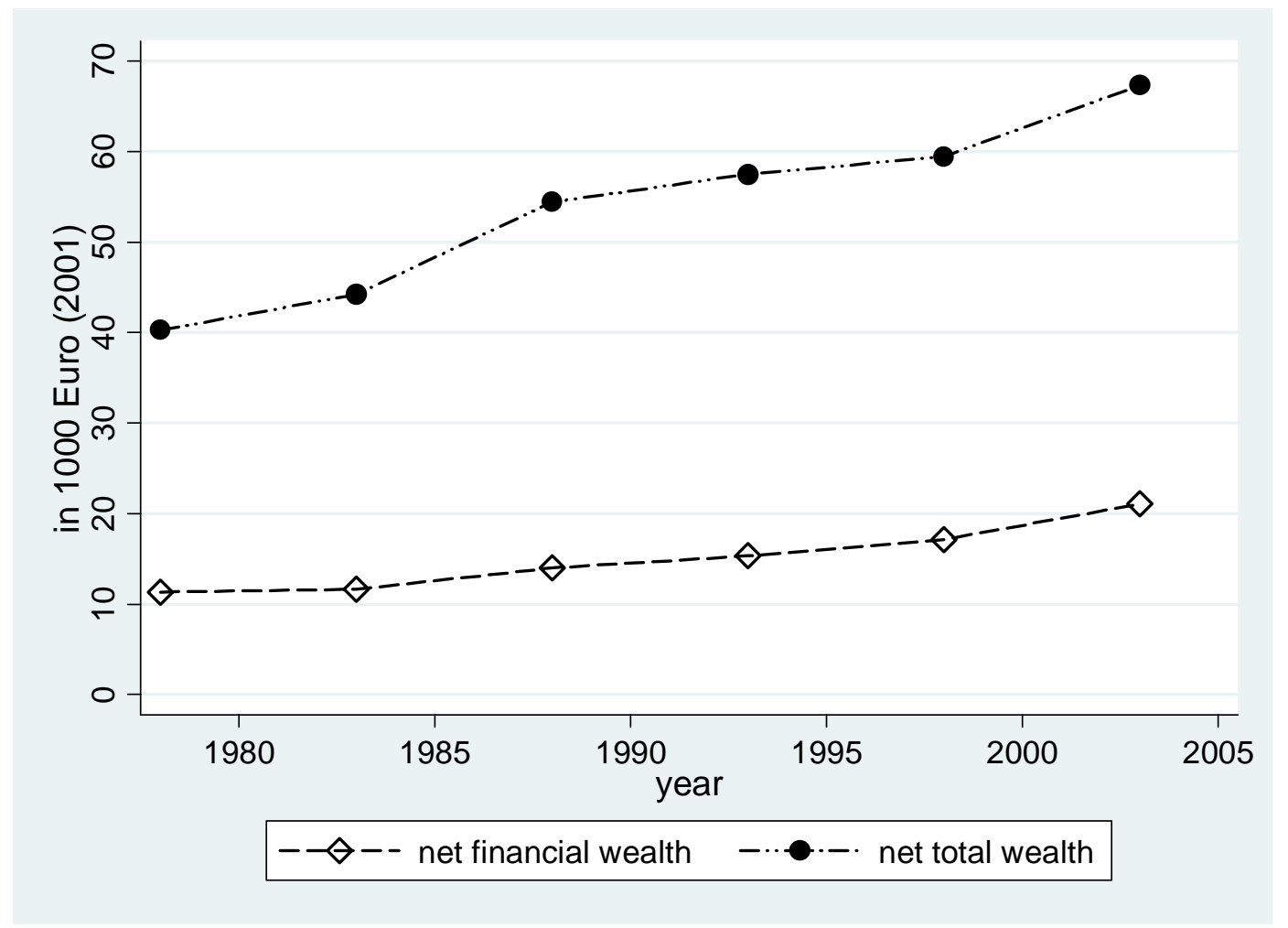

Source: own calculations based on the EVS 1978-2003

Overall, income, consumption, and wealth have all seen rather slow growth over the last decades, especially in comparison with international figures. ${ }^{13}$ Note, that looking at household levels rather than per capita figures, the above growth rates are reduced further as the average household size in Germany has declined over the last decades from about 2.5 individuals per household in 1978 to 2.1 in 2003.

\footnotetext{
13 The OECD (2008) provides comparative time series for household income and consumption. For wealth, we draw our information from the other country chapters of the project "cross-sectional facts for macroeconomists".
} 


\section{IV.2 Trends in inequality}

While the previous section has documented that the historical growth rates in Germany are far from impressive, the rather generous public safety net has traditionally a reputation of achieving more favorable results with respect to inequality. Given that our results are based on data until 2003, we expect little if any effects of the recent reforms to the social security system on the below trends in inequality.

Before turning to the actual trends in inequality we need to make a choice how to measure inequality. Inequality not being a technical term there are different conceptions of what it takes for a distribution to become more equal or unequal. A large variety of inequality measures has been suggested in the literature, each of them with different characteristics when it comes to capturing different aspects of inequality. ${ }^{14}$ For our analysis we focus on the Gini coefficient and the variance of the logarithmized variables of interest. We are aware that other inequality measures are more sensitive e.g. towards inequality at the bottom of a distribution which may especially be a matter of public concern. We nevertheless employ the Gini for its traditional use in the literature and the variance as it is rather intuitive and straightforward to decompose.

For all inequality analyses, we refer to what is commonly denoted as equivalized income, consumption and wealth. ${ }^{15}$ Using household figures, individuals in households with several income earners would be attributed proportionally higher levels of welfare than individuals in households with just one earner. The other extreme would be the use of per-capita data, which disregards returns to scale in consumption. While the first approach will lead to an overestimation of individual wellbeing in all households but single households, the second would equivalently cause an underestimation. The use of equivalence scales therefore aims to integrate the concept of individual utility and consumption in a context where individuals may draw utility from public goods within the household. A variety of adjustment scales have been proposed in the literature. We rely on the OECD equivalence scale which is widely accepted in the literature. ${ }^{16}$ Given that we employ a pseudo-individual measure based on household data, we have to adjust the household weights accordingly. Specifically, we multiply the weight of a household by the

\footnotetext{
${ }^{14}$ For an overview over the most common inequality measures see e.g. Coudouel et al. (2002)

15 The equivalization of wealth data is highly debated in the literature and depends strongly on the assumptions of the use of wealth. As noted in the previous section, we rely on the assumption that wealth is ultimately used for consumption purposes in an unaltered household context. Alternative adjustments e.g. by the number of adult household members implicitly assume that children in the household will not draw utility from the existing stock of wealth.

16 The OECD equivalence scale attributes a value of 1 to the first household member. For each additional adult and underage household member in the household 0.7 and 0.5 are added respectively.
} 
number of its members to ensure that individuals receive equal weight independent of the size of the household they live in.

\section{Income inequality}

No matter whether we measure income inequality by the variance of log income or by the Gini coefficient, we find a clear increase in inequality between the late 1970s and the late 1990s (see figure 3). Between 1998 and 2003, both measures indicate a drop in income inequality back to the level of 1993. Two structural breaks are to be kept in mind. The 1993 data is the first to include also East German households. The changes in inequality within the western and eastern states as well as between the two formerly separated economies have first been investigated by Schwarze (1996) for the years 1990-92. He finds a strong growth in income inequality in the eastern states which is overcompensated by a general catching up of the East with the West. It turns out that the increase in income inequality in the East has continued through the rest of the 1990s as we document in Fuchs-Schündeln et al. (2008). Our analyses based on the GSOEP support the finding from the EVS that the increase in disposable income inequality for the unified country has come to a halt.

Figure 3: Trends in income inequality, Gini coefficient and variance of log income

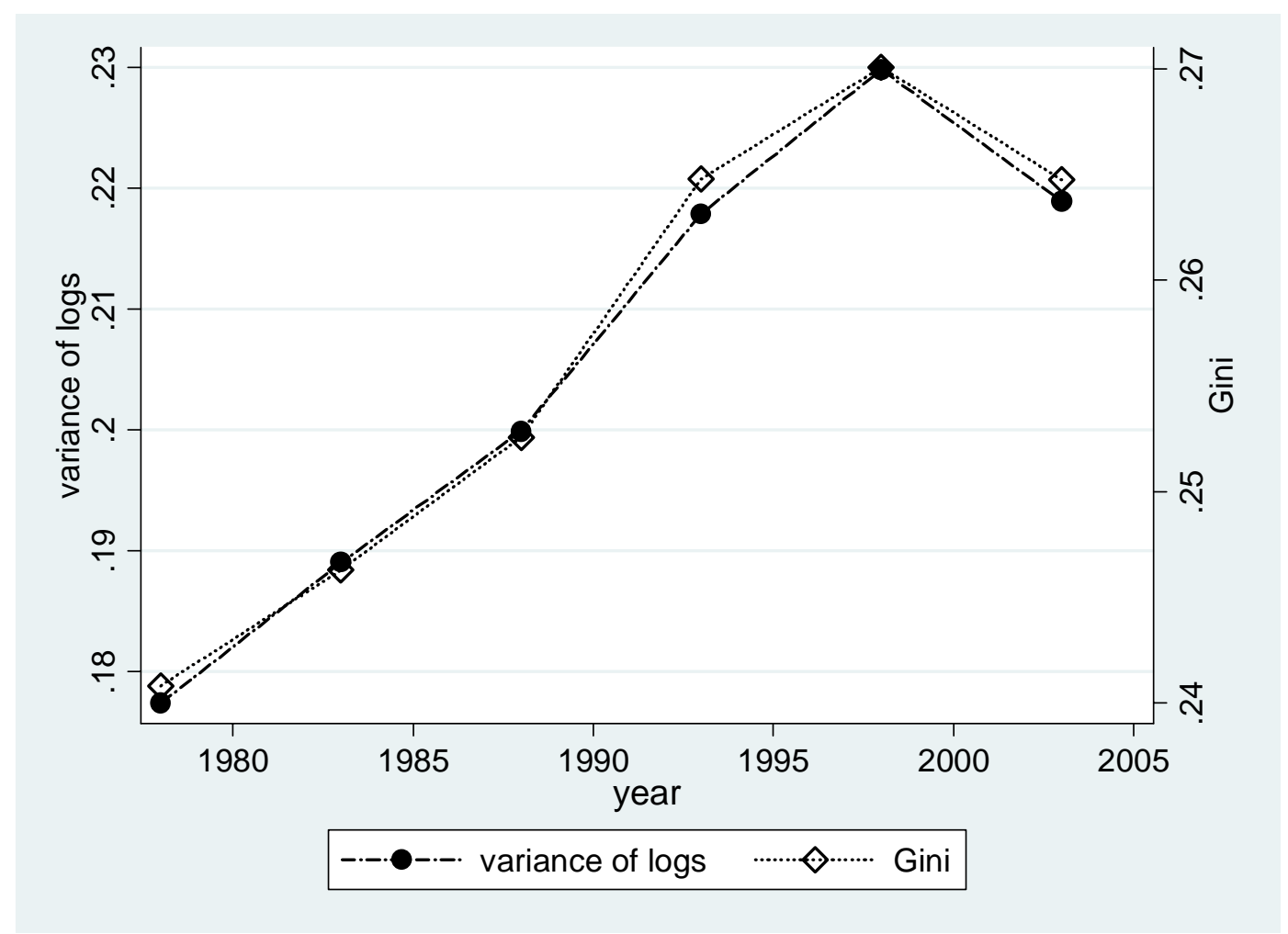

Source: own calculations based on the EVS 1978-2003 
Furthermore there is the switch from annual to quarterly income data in the EVS between 1993 and 1998. It may explain part of the jump in inequality between 1993 and 1998 which seems somewhat larger than what Fuchs-Schündeln et al. (2008) find based on the GSOEP. Their work differs from ours in two aspects: While they focus on the working age-population, we impose no restrictions with respect to age. Further, they employ traditional household weights, where we adjust the weights according to the household size. It turns out that the trends in inequality are quite similar. The level of inequality reported by Fuchs-Schündeln et al. is consistently higher though. Specifically, they report a variance of log disposable income which is about 0.1 higher, roughly 0.03 of which can be attributed to the use of different weights.

\section{Consumption inequality}

Like for income inequality, our two inequality measures yield comparable results. Starting in 1978, we find the degree of non-durable consumption inequality in the same order of magnitude as for income (see figure 4). At the same time, the increase over time turns out to be slightly smaller, especially when we exclude housing expenditures from our definition of non-durable consumption. Looking first at non-durables including housing, consumption inequality has been essentially constant throughout the pre-unification phase. For 1993 and 1998 we observe a small increase in inequality before inequality level recede almost to their pre-unification levels in 2003. Excluding expenditures for housing in our definition of non-durable consumption the trend in inequality roughly follows what we observe for disposable income although the consumption trend is more irregular between 1978 and 1998. We observe a first increase in inequality in the late 1980s and a second one for 1998. The drop in inequality between 1998 and 2003 is consistently found for both consumption definitions and matches our findings for disposable income. 
Figure 4: Trends in consumption inequality, Gini coefficient and variance of log consumption

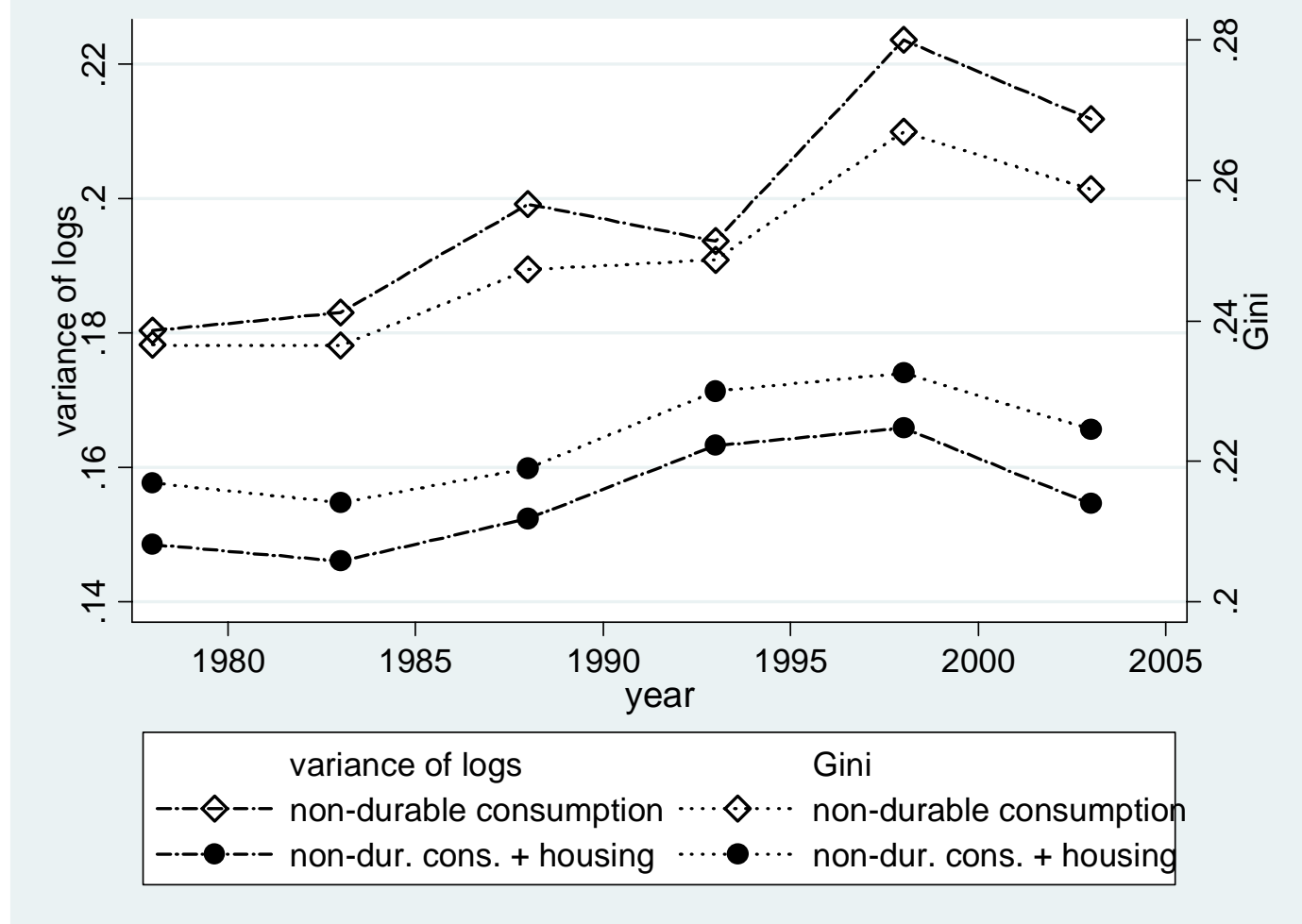

Source: own calculations based on the EVS 1978-2003

\section{Wealth inequality ${ }^{17}$}

Inequality in total net wealth has distinctly increased between 1978 and 1993 and leveled off in subsequent years. The increase in the Gini between 1978 and 1993 amounts to roughly 4 percentage points. Again, the results differ only slightly looking at the two different inequality measures. An exception is the slump in the Gini coefficient for the year 1988 which is unmatched by the variance of $\log$ wealth (see figure 5 ).

Inequality in net financial wealth has seen an even steeper increase, especially in the Gini, which has increased by almost 10 percentage points between 1978 and 1998 and has only leveled off between 1998 and 2003. The increase in inequality measured by the variance of log wealth has been somewhat more moderate. Here, the trend towards higher inequality has not come to a halt though.

\footnotetext{
17 Note, that real estate wealth and wealth in life insurance contracts are fully imputed for the years 1978 through 1988 based on structural information drawn from the 1993 cross-section. The imputation procedures have been carefully chosen to avoid the transmission of undesired distributional characteristics from the 1993 cross-section to the earlier years. Nevertheless, comparisons of distributional characteristics over time should keep this in mind. A full documentation of the imputation procedures is given in Sommer (2008).
} 
Figure 5: Trends in net wealth inequality, Gini coefficient and variance of log wealth

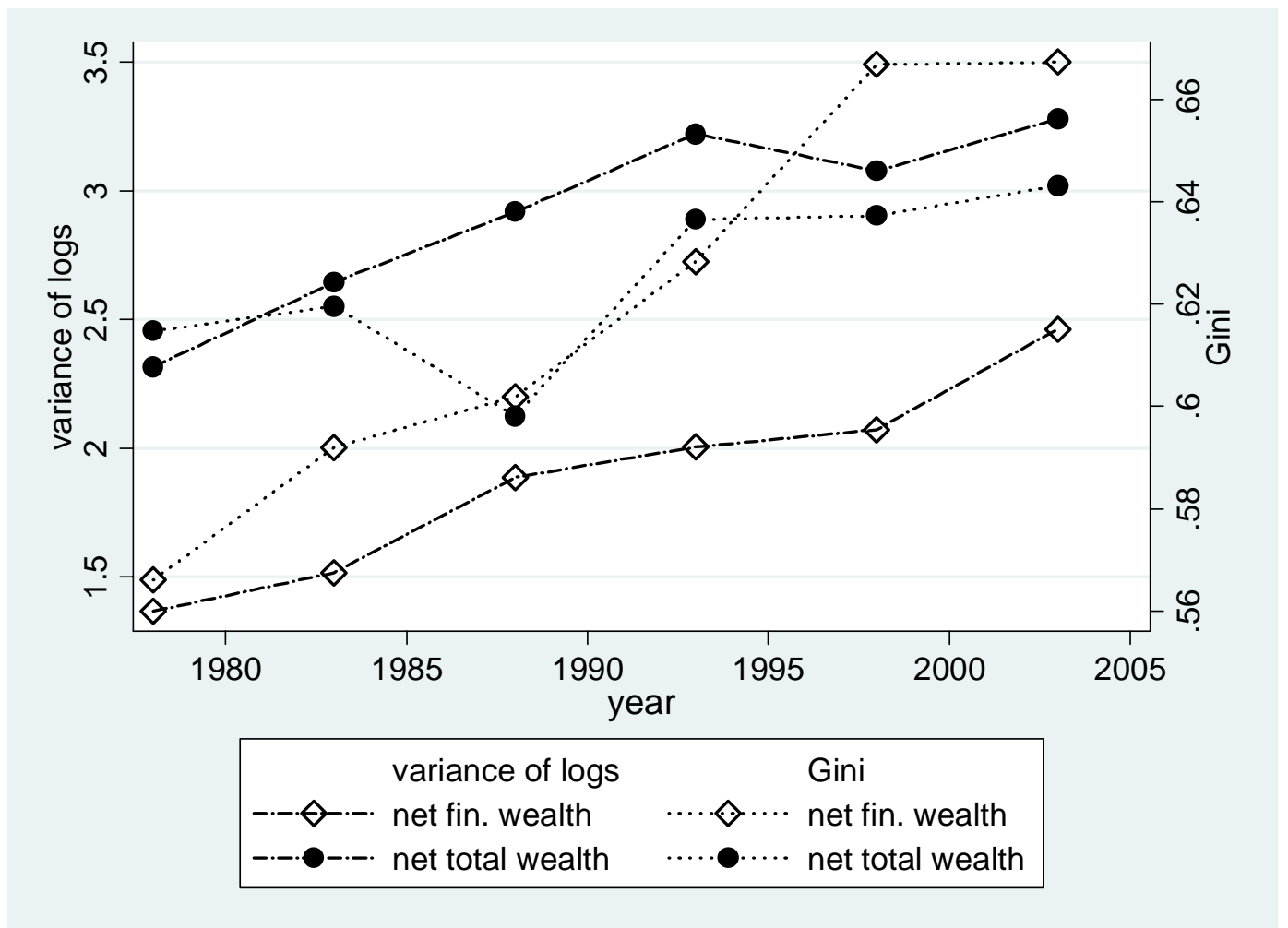

Source: own calculations based on the EVS 1978-2003

Overall we find a much stronger increase in inequality for wealth than for income and consumption. Given that income and wealth are positively correlated, this comes with little surprise, as the existing income inequality is transmitted to wealth through savings. The stronger inequality growth in financial wealth coincides with higher growth rates as we have presented in the first part of this section. We postpone the question to what extent income, savings and wealth appreciation are the drivers behind rising wealth inequality to section six. 


\section{Decomposing the trends in inequality}

Having looked at the aggregate trends in inequality, we now aim to get a deeper understanding of the sources of inequality. We are especially interested in inequality connected to observable household characteristics, as the results can directly be transferred to the introduction of heterogeneous households in macroeconomic models.

Today's standard of modeling economies with a changing demography is to employ an OLG model. The prime characteristic of these models is their setup of the household sector. Rather than using one representative household, they include heterogeneity of households in age. A set of representative households born in different years optimizes over their respective life-cycles. Consequently, differences in the population age-structure are one of the key household characteristics for our decomposition of aggregate inequality. Further examples are differences in household types and heterogeneity in human capital endowments. That differences in human capital endowments can account for a large part of variation in lifetime utility has been shown by Hugget et al. (2006, 2007) as well as by Keane and Wolpin (1997). Ludwig et al. (2007) are an example where such differences in human capital endowment are included into an OLG framework. The empirical benchmarks for the calibration or the evaluation of such models should therefore include the above dimensions of household heterogeneity. For our below analysis of inequality in Germany, we additionally include a distinction of households from the Eastern and the Western states. This is inevitable as since 1990 the population consists of two quite heterogeneous parts which have assimilated over time but hitherto remain somewhat different.

While all of the above household characteristics may be related to inequality, few if any of them can be influenced by political action. Furthermore, to the extent that natural changes in these characteristics are responsible for rising inequality there should be little reason for concern. Possible examples are the trend towards smaller households, especially single households, the German Reunification and the transition of the East German economy, as well as population aging. Where the public and political debate about rising inequality is founded on scientific results little thought is given to such natural trends and differences in inequality. We therefore also aim to strengthen these aspects with new scientific results. An example where public policy will induce rising inequality concerns the recent pension reforms. As the level of public pensions is reduced and replaced accordingly by private savings, wealth inequality will inevitably increase. It is important to understand that this will be case even if the ultimate distribution of retirement incomes remains unchanged. 
Before vivifying the above questions with empirical results, it is helpful to think conceptually about the mechanisms in inequality trends. We show using the example of a variance decomposition that the above changes to the population structure are only one dimension of the possible drivers behind changing inequality. In fact, the total variance in period $t, \sigma_{t}^{2}$, can be written as the weighted sum of the variances within the $k$ population subgroups plus a term driven by the differences between the subgroups' means and the overall population mean $\mu_{t}$ (see equation (1)).

$$
\sigma_{t}^{2}=\sum_{k}\left(\varphi_{k t} \cdot \sigma_{k t}^{2}\right)+\sum_{k}\left(\varphi_{k t} \mu_{k t}^{2}\right)-\mu_{t}^{2}
$$

where

$$
\begin{aligned}
& \mu_{t}=\frac{1}{N} \sum_{i=1}^{N} X_{i t} \\
& \mu_{k t}=\frac{1}{N_{k t}} \sum_{j=1}^{N_{k}} X_{j t} \\
& \varphi_{k t} \equiv \frac{N_{k t}}{N_{t}} \\
& \sigma_{k t}^{2}=\frac{1}{N_{k t}} \sum_{i \in k}^{N_{k t}}\left(x_{i t}-\bar{X}_{k t}\right)^{2}
\end{aligned}
$$

Hence, three components may induce changes to the aggregate level of inequality: First, there may be changes in the means of population subgroups. A classic example is the catching up of the East German economy over the last decades. Second, the level of inequality within population subgroups may change over time. With the rise in inequality within a population subgroup, this carries forward also to the aggregate. Also this second component has played an important role for inequality levels of post-unification Germany. Specifically, inequality in income and consumption has been on the rise in the eastern parts of Germany in the aftermath of the reunification. Third, shifts in the population share of the individual subgroups affect aggregate inequality. The change in a group's weight operates through both of the above channels. If a relatively unequal population subgroup gains weight, also aggregate inequality will increase. Similarly, inequality will rise if subgroups with a group specific average far from the population average gain weight. Equation (2) describes the above formally. 


$$
\begin{aligned}
\Delta \sigma_{t}^{2} & =\sum_{k}\left(\varphi_{k t} \cdot\left(\Delta \mu_{k}^{2}-\Delta \mu^{2}\right)\right)+\sum_{k}\left(\varphi_{k t} \cdot \Delta \sigma_{k}^{2}\right) \\
& +\sum_{k}\left(\Delta \varphi_{k} \cdot \sigma_{k t+1}^{2}\right)+\sum_{k}\left(\Delta \varphi_{k} \cdot\left(\mu_{k t+1}^{2}-\mu_{t+1}^{2}\right)\right)
\end{aligned}
$$

In the following, we present selected results on the drivers behind aggregate inequality. We start with a regression based analysis of the cross-sectional variance in income, consumption and wealth. By construction, we thereby focus on the variance explained by differences in the explanatory variables - in our case key household characteristics. Where applicable, we complement the discussion of the results by facts about the changes in inequality within the respective population subgroups. In the second part of this section, we address the changes in inequality over the life-cycle.

\section{V.1 The importance of sociodemographics for cross-sectional inequality}

To get a first impression of the influence of heterogeneity across households on inequality we analyse, what part of the cross-sectional variance in income, consumption and wealth can be explained by differences between observable household characteristics. To do so, we specify a simple regression model for log income, consumption and wealth. Explanatory variables are the household composition, the age, gender and job education of the household head, as well as the place of residence in the East or in the West. As we include the household composition in the decomposition, we revert to household level data, i.e. we do not apply an equivalization to the data.

Figures 6-9 display what parts of the cross-sectional variance in log disposable household income, $\log$ consumption, and log wealth can be explained by the observable household characteristics mentioned above. We add the residual variance as a point of reference. For a comparison of the decompositions of the early cross-sections (1978-88) and the later cross-sections two important changes are to be kept in mind:

First, there is the addition of the Eastern German population in 1993. The regional dummy will only capture the added variance from the differences in means between the two subsamples. As Schwarze (1996) and Fuchs-Schündeln et al. (2008) show, differences in inequality within the respective parts of the country play an important role for the evolution of inequality at the national level though. We will discuss the effects of the reunification further in the context of the actual results. 
Second, educational attainment is missing in the analysis of the pre-unification years for availability reasons. Thus for the years 1978 to 1988, the dispersion caused by differences in education will be subsumed in the explained variance of correlated variables and in the residual variance. Although the addition of education complicates the comparability of results over time, we decided to add education where possible, as the addition of heterogeneity in education has become a standard extension of macroeconomic models.

\section{Decomposition of income inequality}

Among the household characteristics included in the decomposition, only differences in the household composition account for a considerable part of the variance in log disposable income (see figure 6). Evidently, the variance connected to differences in the household composition increases over time. It turns out that this is largely caused by the proliferation of households at the extremes of the income distribution. The key reason is the trend towards single households. The incomes of single households have seen above average growth rates between 1978 and 2003 but remain at the bottom of the income distribution. At the same time, the share of single households in the population has increased by roughly one third from 27.7 percent in 1978 to 38.8 percent in 2003. The increased number of single households has therefore overcompensated the inequality reducing effects of favorable income growth among single households.

Noteworthy are also the regional dummy and the educational attainment of the household head. Both explain about a third of the variance explained by differences in the household type. While the explanatory power of education is fairly constant over time, the importance of the East/West distinction decreases considerably, indicating that the gap between disposable incomes in East and West Germany has shrunk. The effects of different levels of inequality within the respective regions are apparent in the slump in the residual variance in 1993. At that time, the level of inequality within the East was still substantially smaller than in the West, causing a drop in inequality at the national level. 
Figure 6: Decomposition of the variance of log disposable household income

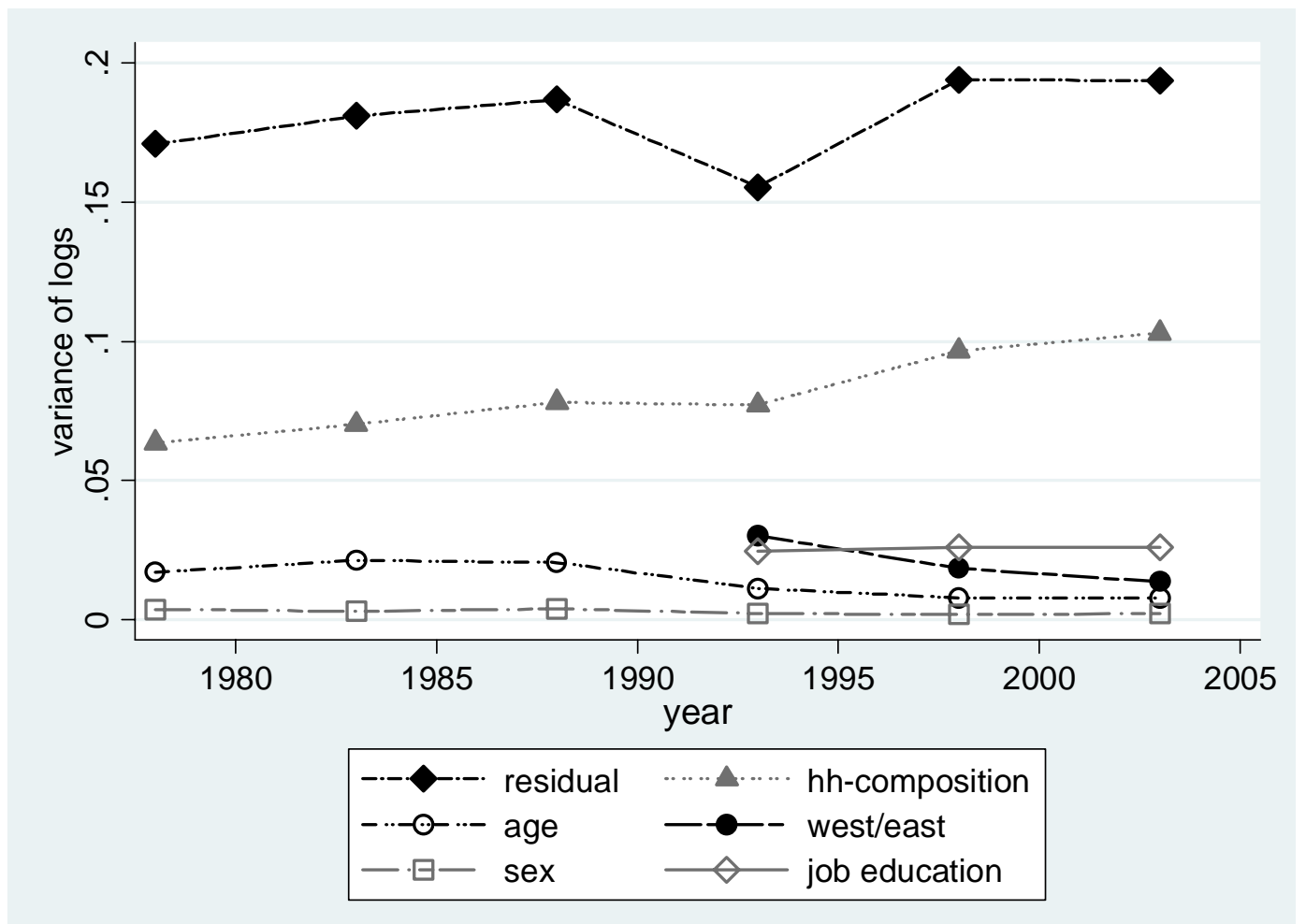

Source: own calculations based on the EVS 1978-2003

\section{Decomposition of consumption inequality}

The pictures for income and consumption inequality look quite alike (see figure 7). The main difference is the smaller and decreasing residual variance in consumption where we had observed a slight increase in the residual variance for income.

Like for income, differences in the household composition explain a great deal of consumption inequality. Education has a constant explanatory power in a similar order of magnitude as for income. However, there is little direct reason why education should matter as much for consumption as it does for income. An exception might be a higher willingness of higher educated households to invest in further education, quality food and health. Yet it seems much more likely, that differences in income related to different educational attainments carry over to consumption possibilities and ultimately to expenditures. The same argument can be transferred to our regional distinction. In fact, the variance connected to the differences in consumption and income between the East and the West has more than halved between 1993 and 2003. We omit the corresponding graph for our alternative definition of non-durable consumption for brevity as the results show no remarkable differences. 
Figure 7: Decomposition of the variance of log non-durable consumption (incl. housing)

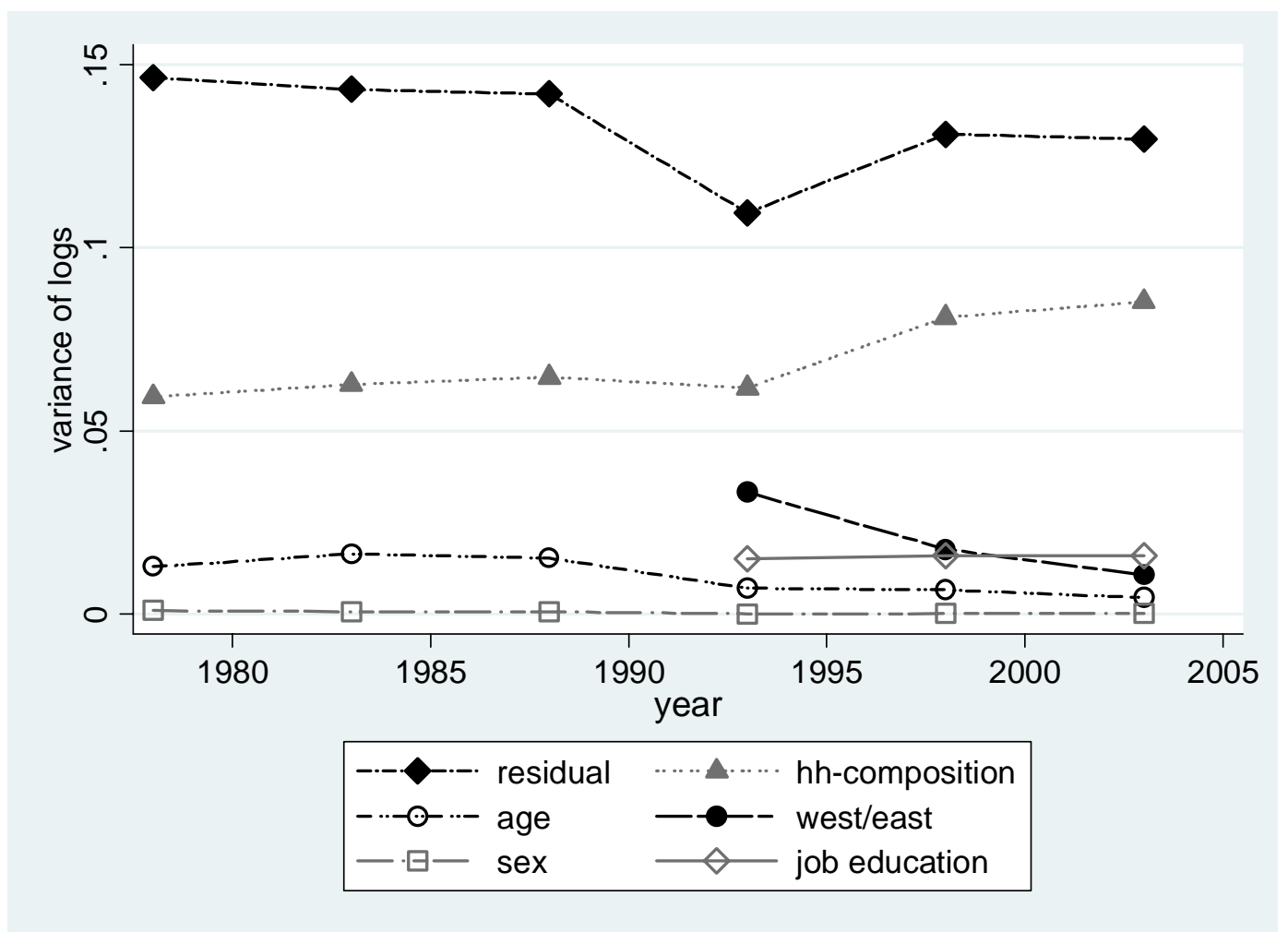

Source: own calculations based on the EVS 1978-2003

\section{Decomposition of wealth inequality}

Last, we turn to the question what part of the wealth dispersion can be explained by observable differences between households. Figure 8 strikingly illustrates, that none of the household characteristics employed in the decomposition accounts for a relevant part of financial wealth inequality. Among the tightly cramped lines at the bottom of the graph, only age and the East/West distinction catch the eye. Concretely, a small but increasing part of the variance is connected to the age-structure of the population. At the same time, the differences in wealth holdings between West and East have declined over time, as observed previously for income and consumption. Also for net total wealth, the observed household characteristics explain rather little of the overall dispersion (see figure 9). Again, the East/West dummy explains a certain but diminishing part of the variance in total wealth, age a similar, though slightly increasing amount. The remarkable difference comparing the variance in net financial and net total wealth concerns the role of differences in household composition. Only for total wealth, variation in wealth levels across household types plays a role. The reason is differential home ownership across household types: In fact, only about 26 percent among households with one adult own real estate, but 54 and 72 percent of the households with two and three adults respectively. 
Figure 8: Decomposition of the variance of $\log$ net financial wealth

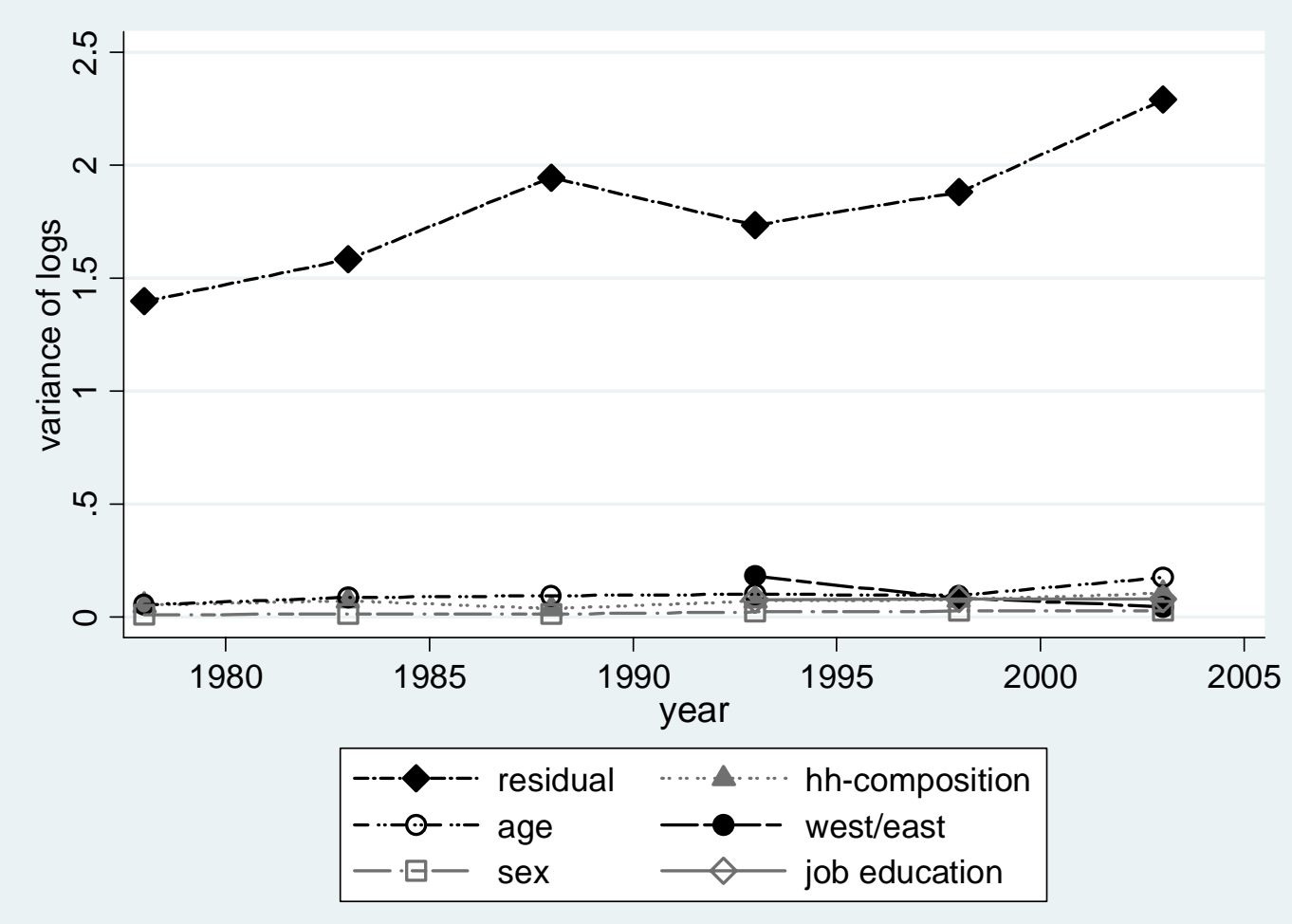

Source: own calculations based on the EVS 1978-2003

Figure 9: Decomposition of the variance of $\log$ net total wealth

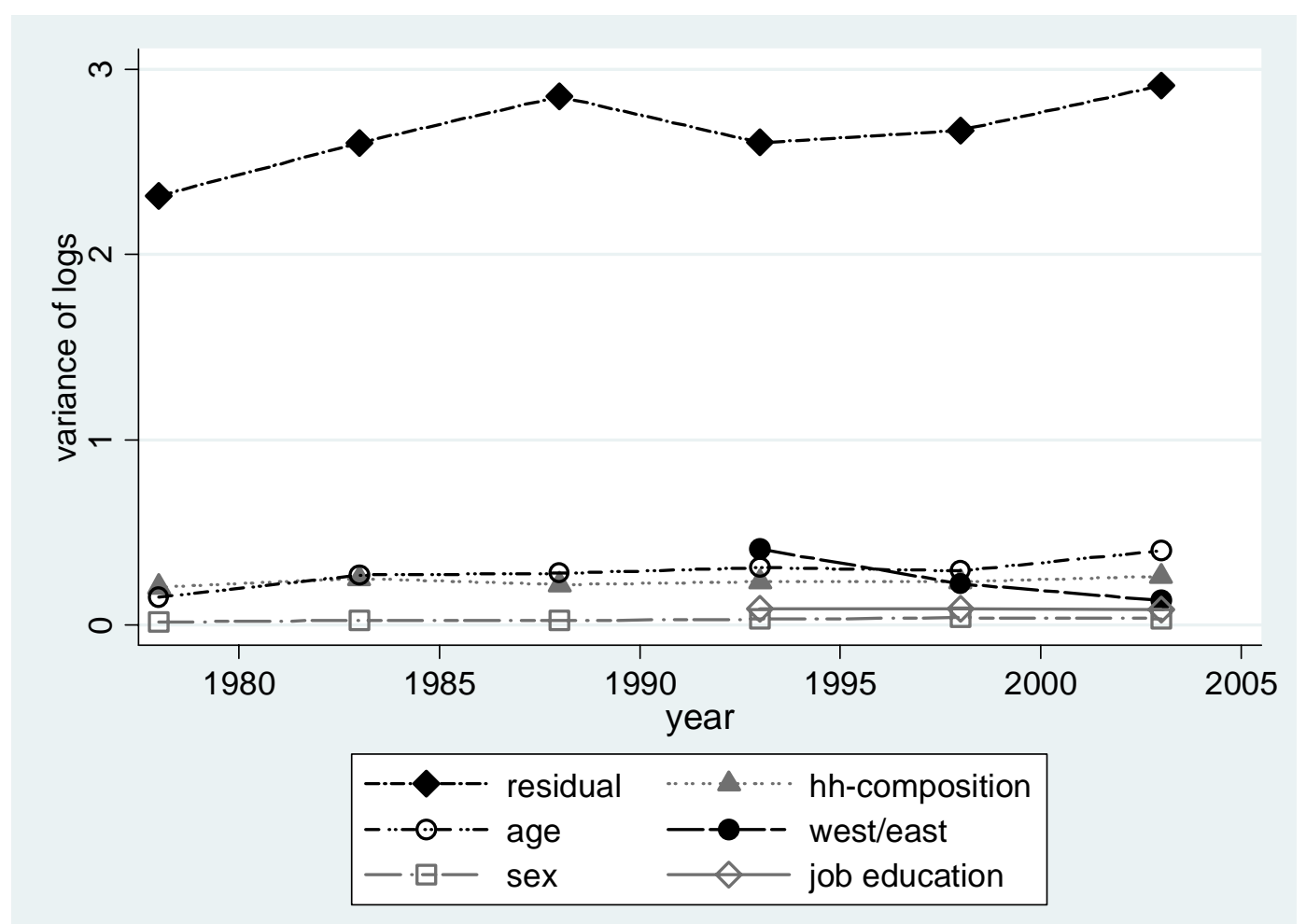

Source: own calculations based on the EVS 1978-2003 


\section{V.2 Evolution of inequality over the life-cycle}

Overall, the above cross-sectional decompositions of inequality in income, consumption and wealth have revealed a number of important coherences. A substantial part of the dispersion in income and consumption is connected to different household types, which highlights the necessity to employ an equivalence scale in the assessment of inequality. Further, looking at the national trends in inequality in Germany, it is important to account for the German reunification. While the effects of the reunification are rather well understood, much less is known about the effects of a changing population age-structure.

In the introduction of this section, we have proposed a general structure for the factors behind changes in inequality. We now apply these to the context of an aging society using the example of income inequality. The transfer to consumption and wealth inequality is straightforward.

First, there are differences in average income across age-groups which we typically think of as the life-cycle income profile. It exhibits a hump shape with a steep increase over the first decades in the work force. Around age 50, average income levels off before it declines for the following agegroups due to rising unemployment rates and early retirement. Income levels drop considerably between age 60 and 65, as the cohort gradually goes into retirement. Thereafter, average income is essentially flat for the oldest age-groups. If the life-cycle income profile grew steeper with larger distances of the average income of certain age-groups to the overall average, this would ceteris paribus increase the overall level of inequality. However, the results from the crosssectional decomposition above indicate that differences between age-groups play only a minor role for the overall level of income inequality.

Second, the level of inequality within the individual age-groups may increase. Thinkable reasons would be a rising dispersion in market wages or hours worked. Given that we are looking at postgovernment income also the government sector may play a role. Examples would be changes in the income tax scheme or in the payment of government transfers.

Third and last, the population age-structure may change and thereby shift weight to or from agegroups with extremely low or extremely high income levels. In the same manner, population weight may be shifted from rather unequal age-groups to more equal ones and vice versa. If fact, the retirement of the baby-boom generation will shift weight away from the highest income agegroups. Whether inequality among the working age-population is higher or lower compared to the first post-retirement age-groups is to be determined in the subsequent analysis. Unless the inequality age-profile is flat, gradual effects on the distribution of incomes and consumption can be expected as more and more baby-boomers retire.

In the following, we focus on differences in inequality between age-groups to assess the possible effects of changes to the population age structure on aggregate inequality. To elicit an age-profile 
in inequality from our synthetic panel data, we have to take a stand with respect to time- and cohort effects. ${ }^{18}$ We alternatively assume time- and cohort-effects to be zero and compare the resulting age-profiles.

Specifically, we estimate for both inequality measures $I$ an OLS regression including age-group dummies $A$ based on the age of the household head and year dummies $Y$, as described in equation (3). The alternative cohort-specification includes cohort dummies $\mathrm{C}$ instead of the agedummies, as described in equation (4).

$$
\begin{aligned}
& I_{a t}=\alpha+\sum_{a} \beta_{a} \cdot A_{a t}+\sum_{t \neq 1} \tau_{t} \cdot Y_{a t}+\varepsilon_{a t} \\
& I_{a t}=\alpha+\sum_{a} \tilde{\beta}_{a} \cdot A_{a t}+\sum_{c \neq 1} \gamma_{c} \cdot C_{a t}+\varepsilon_{a t}
\end{aligned}
$$

The resulting life-cycle profile of inequality is then computed as follows:

$$
\hat{I}_{a}^{T}=\alpha+\bar{\tau}+\sum_{a} \beta_{a} \cdot A_{a t} \quad \text { and } \quad \hat{I}_{a}^{c}=\alpha+\bar{\gamma}+\sum_{a} \tilde{\beta}_{a} \cdot A_{a t}
$$

The inclusion of the average year- and cohort-effect implies that the levels of our results can be interpreted as the age-profile for an average year and an average cohort respectively.

\section{Age-profiles in income inequality}

The results for income turn out to be rather sensitive with respect to the chosen specification (see figure 10). At the same time, the two inequality measures yield closely comparable results. Based on the time-effects specification we find a relatively flat age-profile. Inequality is smallest for the youngest age-groups. What follows is a two-step increase in income inequality towards the age-group 30-34 and then again between age 50 and age 64. In between, the level of inequality remains flat or decreases slightly. Inequality peaks for the age-group 60-64 and declines in the following 10 years. The remainder of the age-profile is flat again. If we think of a baby-boom generation moving through this stylized life-cycle, we can expect aggregate inequality to increase as the baby-boom generation moves through their last years in the labor force and to revert to its previous level as the baby-boomers reach age 70 and above.

\footnotetext{
18 By construction, age-, time-, and cohort-effects are perfectly collinear in a linear specification. Identification therefore relies on assumptions or the functional form of the specification (see Deaton and Paxson (1994), Brugiavini and Weber (2001), or Ameriks and Zeldes (2001))
} 
The age-profile estimated from the cohort-specification looks similar in its swings over the lifecycle, but tilted by about $25^{\circ}$ to be strongly upward sloping. The clearly different life-cycle path of inequality derived from the cohort-specification gives reason to investigate the underlying raw data in more detail. It turns out that the major shifts in income inequality have affected essentially only the working age population. ${ }^{19}$ Much of the results may therefore be driven by the assumptions implicit to the regression model. Specifically, the specification implies that time- and cohort-effects cause parallel shifts to an otherwise unaffected age-profile. The raw data suggests that neither assumption is justified for all age-groups. While a closer look at the raw data is probably the best way to understand the historical trends in inequality, the complex evolution makes things somewhat more difficult for macroeconomic modeling. In fact, income inequality over the life-cycle used to be much steeper in the past and has flattened out in recent years. Such structural changes throughout the historical data used for the calibration pose a challenge for projections.

Figure 10: Age-effects in equivalized post-government income inequality

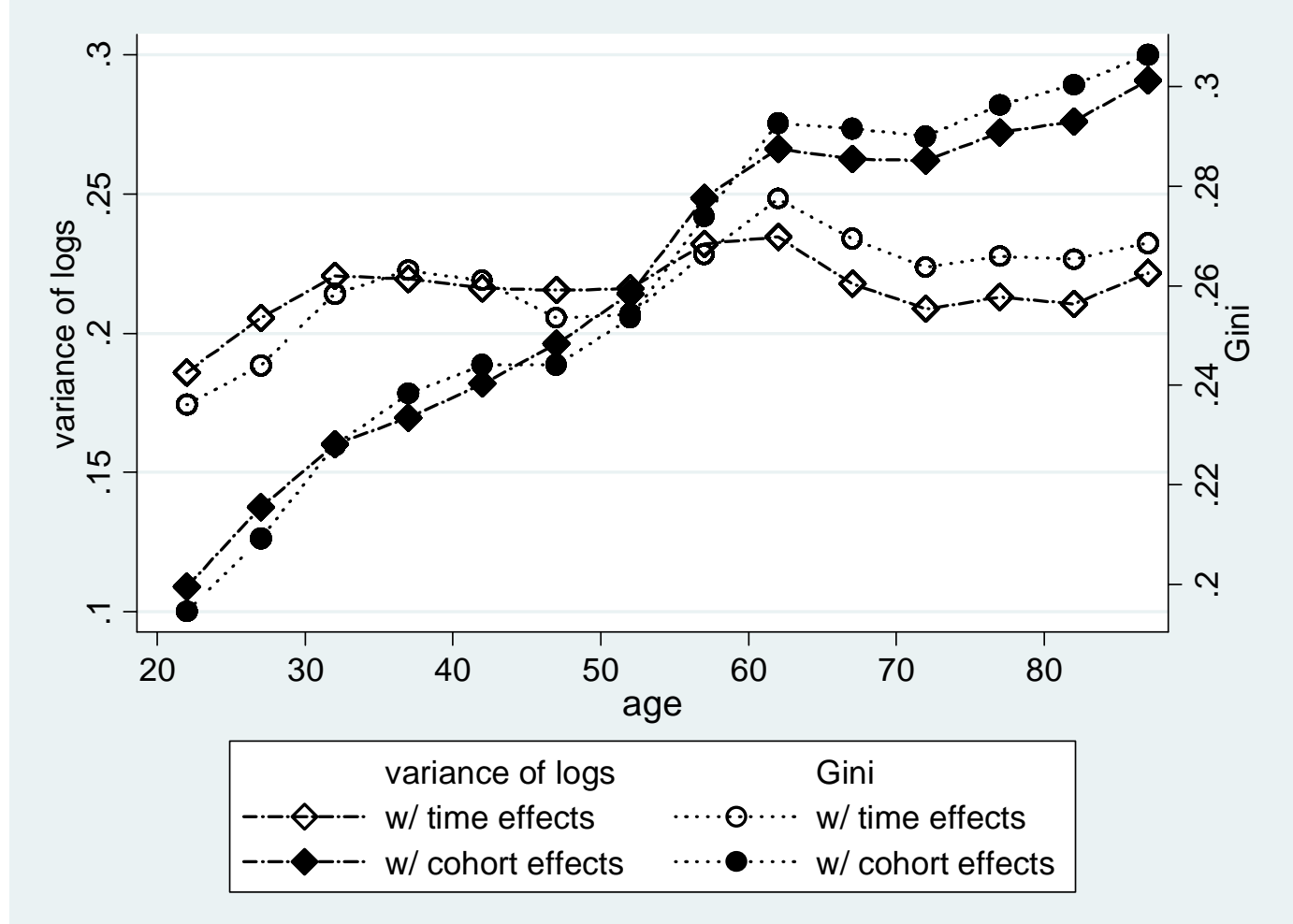

Source: own calculations based on the EVS 1978-2003

19 The appendix contains a cohort-graph of the raw inequality data. 


\section{Age-profiles in consumption inequality ${ }^{20}$}

Consumption inequality does not exhibit the issues we observe for income inequality. Not only the different inequality measures but also the different specifications yield quite similar ageeffects. We find a continuously increasing level of inequality over the life-cycle (see figure 11). The age-trajectories are flat only between age 30 and 50 and then again beyond age 75 . For part of inequality trends in an aging society, the upward slope of the age-profile suggests that consumption inequality will continuously increase over time as the population weight shifts towards older age-groups. However, this effect is attenuated by the age-profile in consumption levels. Specifically, average consumption levels after retirement are much closer to the population mean than the consumption levels of those age-groups immediately before retirement.

Figure 11: Age-effects in equivalized non-durable consumption inequality

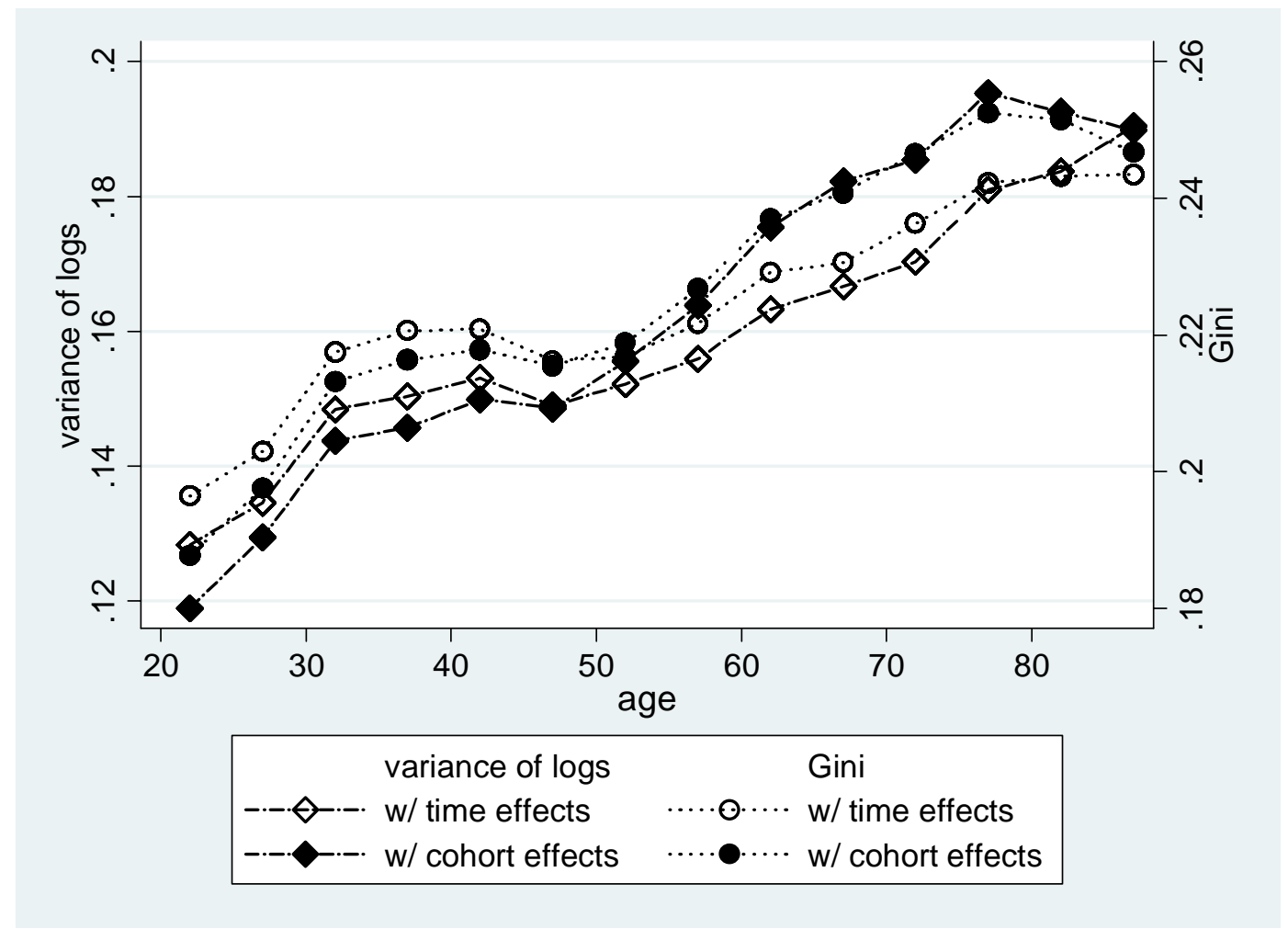

Source: own calculations based on the EVS 1978-2003

\footnotetext{
20 We only present results based on non-durable consumption including housing expenditures for brevity. The results from our alternative definition show only minor deviations.
} 


\section{Age-profiles in wealth inequality}

Figures 12 and 13 present the results on life-cycle inequality in net financial wealth and net total wealth respectively. Much more than for the case of income inequality, the results based on different specifications and inequality measures yield different results.

Employing the cohort specification, we find a strongly upward sloping age-profile for both wealth measures based on the variance. Looking at the results for the Gini coefficient, the general life-cycle pattern resembles a u-shape. For financial wealth, inequality bottoms out around age 40 and the upward slope over the remaining life-cycle clearly dominates the downward slope among the early age-groups. For total wealth, the pattern is shifted and tilted to the right. Inequality levels decline until age 55 and increase only slightly thereafter.

Figure 12: Age-effects in equivalized net financial wealth

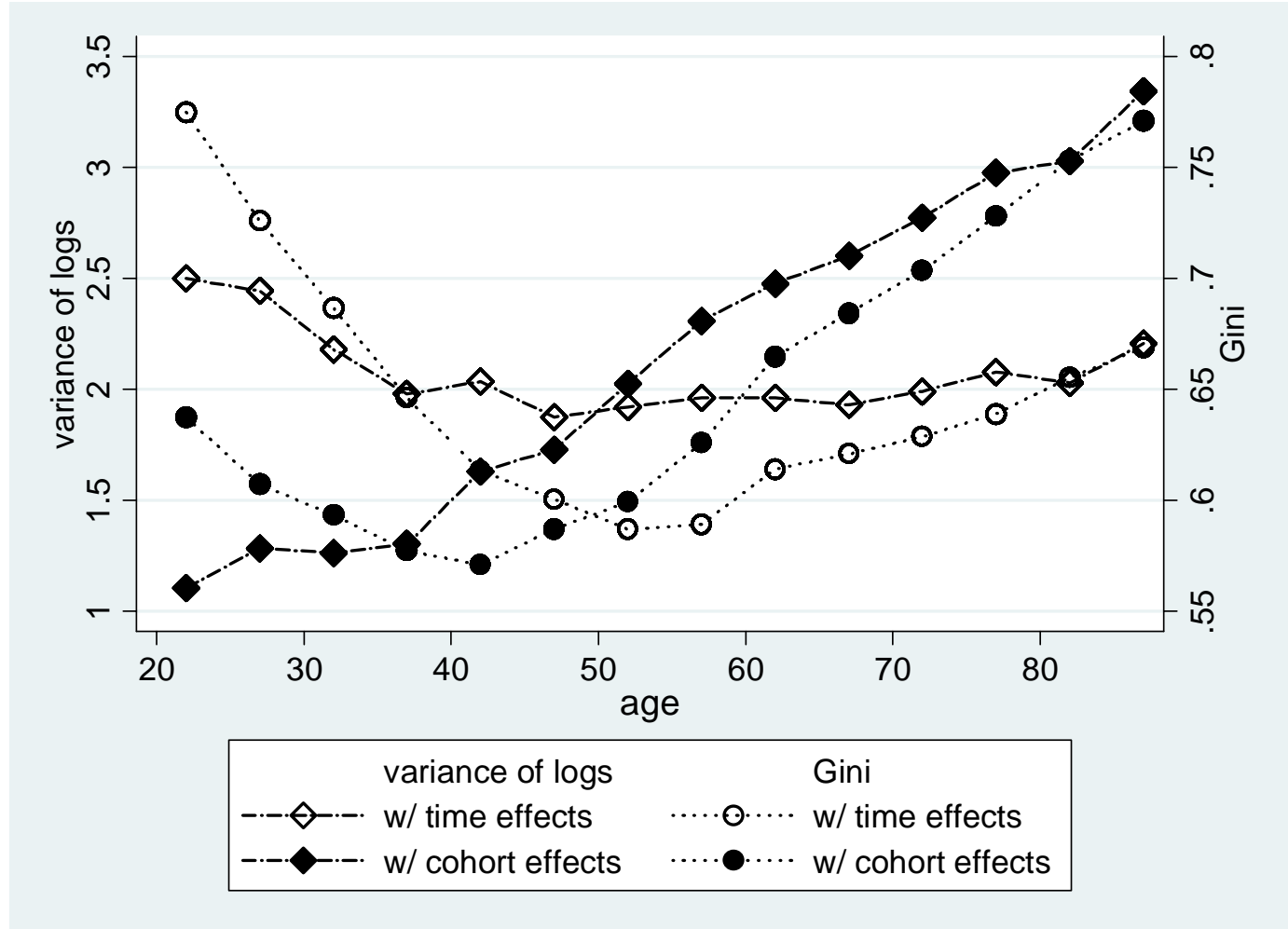

Source: own calculations based on the EVS 1978-2003

Looking at the results based on the time-effects specification we find the above age-profiles to be clockwise rotated. However, there is a considerable amount of variation in the degree of rotation to the age-profiles.

Overall, the results for life-cycle wealth inequality are strikingly ambiguous. Especially surprising are the differences between the two inequality measures. The raw data exhibits a u-shaped cross- 
sectional age-profile for both measures. ${ }^{21}$ At the same time, the different slopes over the life-cycle of cohorts shed some doubt that wealth inequality actually takes a u-shaped path over the lifecycle. In fact, the age-trajectories of individual cohorts based on the Gini are mostly flat or downward sloping, whereas the variance trajectories are remarkably upward sloping. Furthermore, the raw data suggests only minor differences between cohorts based on the Gini. Based on the variances of $\log$ wealth, we find the individual cohort trajectories much further apart.

Figure 13: Age-effects in equivalized net total wealth

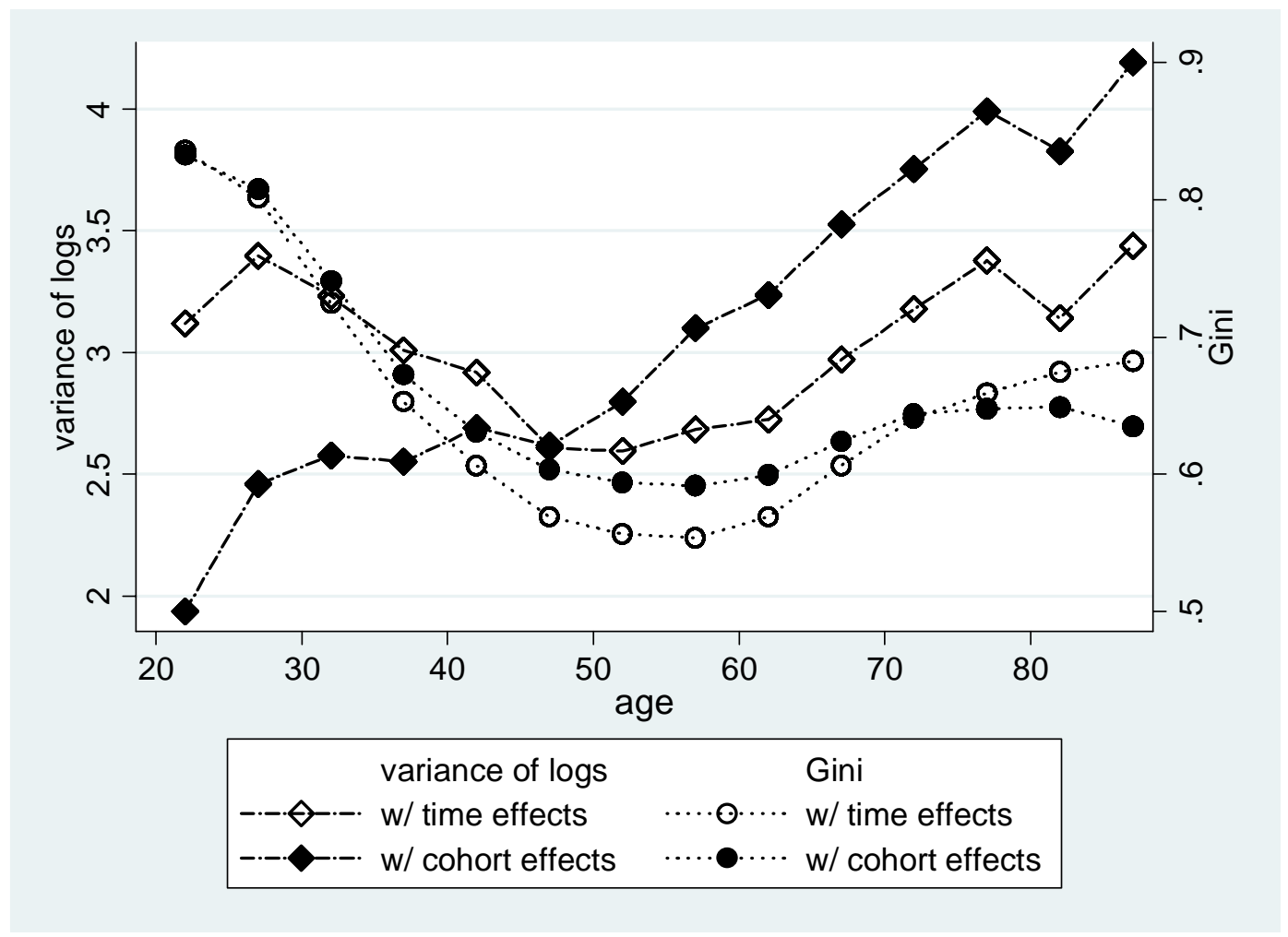

Source: own calculations based on the EVS 1978-2003

The different sensitivity of the two inequality measures with respect to extreme values may help us resolve the puzzle and add further insights. The variance being more sensitive to outliers we suggest that wealth inequality is rather stable across cohorts and over age with an exception of extreme values. At the same time, the number of extremely wealthy households increases over the life-cycle. Further, younger cohorts tend to contain more extremely wealthy households than the generation of their parents did at the same age.

${ }^{21}$ A cohort-graph of the raw data is presented in the Appendix. 


\section{Relating the expansion of wealth inequality over the life-cycle to savings, asset allocation and inheritances}

We have documented in the previous sections, that wealth is much more unequally distributed than income and consumption. In addition, wealth inequality has increased over the last decades. Conceptually, both findings are rather unsurprising, as wealth is a stock variable. Changes to the existing stock of wealth are first of all driven by savings and appreciation. Savings in turn depend on income, which is highly correlated with wealth. Given that in Germany even among retired households only one in four is actually dissaving, savings can be expected to have largely dispersing effects on the wealth distribution. The same applies to appreciation effects. As long as real returns are positive, the effects of asset appreciation on wealth inequality should also be dispersing - at least in absolute terms. Hence, mainly inter-vivos transfers seem suited for wealth decumulation. However it is arguable, whether the intergenerational transmission of wealth through inter-vivos transfers and bequests has had equalizing effects on the wealth distribution in the past. Kohli et al. (2005) compare the actual wealth distribution with a counterfactual where they eliminate received wealth transfers. They find a slightly higher level of inequality in the case without transfers. Westerheide (2004) investigates the propensity to consume out of received transfers and finds it to be higher among the rich. Consequently, they both tend to attribute wealth transfers an equalizing effect. At the same time, they both document a strong income and wealth gradient in received wealth transfers. While poor households have profited more in relative terms, the absolute differences in transfers received remain large.

Overall, all the above factors lead to a relatively small level of mobility within the wealth distribution - especially compared to income - as shown by Jianakoplos and Menchik (1997). ${ }^{22}$ While there is a certain literature assessing the connections between life-cycle savings and wealth inequality (e.g. Pudney (1993), Hendricks (2002)), we are not aware of a more comprehensive analysis of the drivers behind wealth inequality in a life-cycle context. In the following, we aim to fill this gap based on a parsimonious model of wealth accumulation which we apply to the German EVS data.

\footnotetext{
22 Other analyses investigate wealth mobility as such (e.g. Edlund and Kopczuk (2007), Steckel and Krishnan (1997)).
} 


\section{VI.1 A parsimonius model of wealth accumulation}

Changes in wealth holdings over time can be classified into savings, appreciation and wealth transfers. In a household context, also the formation and the dissolution of households will play a role. Given that a well founded analysis of household formation effects on wealth holdings should be based on panel data, we defer this question for future research.

We think of wealth accumulation as presented in equation (5):

$$
a_{t+1}=a_{t} \cdot\left(1+r_{t}\right)+s_{t}+t_{t}
$$

Wealth in period $t+1$ consists of wealth in period $t$ which has appreciated by the real rate of return $r$. Further, savings $s$ and net transfers $t$ received in period t are added. This equation of motion can be rewritten and expanded as follows:

$$
\Delta a_{t}=a_{t+1}-a_{t}=a_{t} \cdot \underbrace{\left.\sum_{k} \varphi_{k t} r_{k t}\right)}_{r_{t}}+s q_{t} \cdot y_{t}+\underbrace{t_{t}^{R}-t_{t}^{G}}_{t_{t}}
$$

Thus, wealth growth consists of three components: First, there is the appreciation effect, which depends on the real returns $r$ of the $k$ individual assets and their portfolio shares $\varphi_{k}$. This first component of wealth growth is often denoted as passive savings. Second, there is the effect of active savings, i.e. the value of net asset purchases, net contributions to insurance contracts and savings accounts, as well as net repayments of debt. This can also be expressed as the net savings rate $s q$ multiplied by the contemporary disposable income $y$, which illustrates the influence of the income distribution on the wealth distribution. Last, there are net transfers which can be split into received transfers $t^{R}$ and given transfers $t^{G}$. In practice, these transfers can take the form of inter-vivos transfers or inheritances.

\section{VI.2 Estimating stylized life-cycle profiles of wealth accumulation}

The above general considerations can easily be applied to a life-cycle context. In panel data we would follow the savings and the portfolio choice of households over time. Thus, starting from 
initial wealth holdings we could add the observed active savings and the known net transfers. Further, we could estimate the expected appreciation effects from the known portfolio allocation. Given that we only have repeated cross-sectional data available, we revert to using groups of households sharing the year of birth of their household head for the construction of a synthetic panel. The household level data is replaced accordingly by cohort averages of wealth, savings, and portfolio shares, as we observe them at different ages over time. We define cohorts such that households from adjacent years of birth are grouped together. To provide insights into the different mechanisms of wealth accumulation among households with high and with low savings capacity, we further stratify the cohorts by their position in equivalized income distribution of the cohort. Put differently, we ultimately follow the wealth holdings, the savings and investment behavior of the top, upper middle, lower middle and the bottom of the income distribution of each birth cohort over their pseudo life-cycles.

To actually interpret the life-cycle wealth growth trajectories of the cohorts defined as above, we have to insure that cohorts remain homogeneous over time as far as possible. First of all, we therefore exclude the East German sample and focus only on West German households. Furthermore, households should ideally be attributed to the same cohorts in case they are sampled several times over the years. The assumption that households remain in the same birth cohort may not do too much harm. A household will only be attributed to a different birth cohort if there is a change in the household head. Given that we define the household head to be the oldest male, such a switch in household headship will essentially only occur if the household head leaves the household or dies. ${ }^{23}$ The second assumption is a much more problematic one. While the relative income position of households within a cohort tends to relatively stable between age 35 and age 55, income mobility plays a more important role in the phase of job market entry and exit. We therefore carefully interpret our results and discuss the direction of the effects of income mobility.

For the actual projection of wealth accumulation we proceed as follows: For each birth cohort and each year, we split the distribution of equivalized household disposable incomes in four parts. The top income decile, the $7^{\text {th }}-9^{\text {th }}$ income decile ("upper middle"), the $4^{\text {th }}-6^{\text {th }}$ income decile ("lower middle") and the bottom three income deciles. In the following, we denote these fragments of the income distribution as quartiles. For each quartile $y$ of each birth cohort $c$ at a given age $a$ we estimate the growth in wealth per adult capita over the following five years. We

\footnotetext{
${ }^{23}$ In the absence of male household members we choose the oldest female to be the household head.
} 
choose a per adult capita measure to minimize the distorting effects of changes to the household composition. $^{24}$

For the actual estimation of the wealth growth through asset appreciation, we apply the observed average portfolio allocation to the initial average level of wealth (see equation 7). For the real returns of the individual asset classes, we deliberately decided against year-specific returns. The fluctuations in nominal returns and inflation rates over time have been comparatively large. Furthermore, we are foremost interested in the conceptual differences of wealth growth at different ages and for households at different positions in the income distribution. Therefore, incorporating the historical fluctuations in real returns seemed detrimental. We generally apply equal asset returns for all income quartiles and age-groups, although differences in financial literacy and restrictions in access to certain assets would imply an income gradient in asset returns. The main reason is that we have no means to quantify the suspected differential returns. An exception is housing wealth, where we estimate the differential growth rates for the income quartiles from the EVS data. ${ }^{25}$

$$
\Delta a_{c y a}^{A}=\left(\left(1+\sum_{k} \bar{\varphi}_{c y a k} \bar{r}_{y k}\right)^{5}-1\right) \cdot \bar{a}_{c y a}
$$

In the results below, we break down the appreciation effects further into real wealth, financial wealth and debt.

To estimate the wealth growth through active savings we project the average annual savings $\bar{s}_{c y a}$ of each cohort-age-quartile cell to the next five years (see equation 8). We thereby assume constant savings over the unobserved following four years. Given the short horizon of the projection of only five years, the inaccuracy induced by this assumption can be expected to be small for the vast majority of age-groups. Given that over five years, the new savings already earn interest, the projected five-year savings have to be augmented accordingly. For simplicity we assume that the new savings are allocated like the existing stock of wealth and therefore apply the

\footnotetext{
${ }^{24}$ Using plain household levels, our results would be strongly affected by household formation and dissolution. Employing an equivalence scale which includes the children in the household, equivalent savings would depend on the birth or the moving out of children over the life-cycle of their parents. Only in the case of death of an adult where the remaining adult member inherits the stock of wealth using per adult capita measures can be expected to have distorting effects on the life cycle wealth path.

25 The returns used for the projection are tabulated in the appendix, which also contains a description of our procedures of estimating the differences in housing price growth across income quartiles.
} 
same rate of return. Furthermore, we include the additional appreciation of savings in active savings although these wealth gains should conceptually be counted as passive savings.

$$
\Delta a_{c y a}^{S}=\bar{s}_{c y a} \cdot \sum_{t=1}^{5}\left(1+\bar{r}_{c y a}\right)^{t-1} \quad, \text { where } \quad \bar{r}_{c y a}=\sum_{k} \bar{\varphi}_{c y a k} \cdot \bar{r}_{y k}
$$

Last, there are average net transfers received. If possible we would proceed equivalently to the case of savings and project the known net transfers from the years of observation to the following four years for which we have no data as described by equation (9).

$$
\Delta a_{c y a}^{T}=\left(\bar{t}_{c y a}-\bar{t}_{c y a}^{G}\right) \cdot \sum_{t=1}^{5}\left(1+\bar{r}_{c y a}\right)^{t-1}
$$

Unfortunately, we cannot distinguish bequests and gifts from support payments and other income streams between households in all years. Thus, we initially restrict our core model to the effects of active and passive savings. Total wealth growth of the cohort-quartiles over the following five is therefore calculated by

$$
\Delta a_{c y a}=\Delta a_{c y a}^{A}+\Delta a_{c y a}^{S}
$$

To get as close as possible to a comprehensive picture of the drivers behind wealth growth, we add a cross-sectional breakdown of received inheritances based on the EVS 2003. While this implies that we disregard possible cohort effects in inheritances it is simply the closest we can get given the available data.

\section{VI.3 Results for a broadly based cohort}

Before turning to the stylized age-profiles, we have a look at the raw results for a single broadly based cohort. The purpose is twofold: first, looking at the raw projections, we avoid the effects of the assumptions involved in the extraction of age-effects. Second, we deliberately choose a wide cohort for this exercise which includes households from 15 adjacent years of birth. Thereby we aim to convey the best-possible impression of how the German population has accumulated wealth over the last decades without entirely giving up the life-cycle context.

To do so, we focus on a cohort which we can observe over most of their working life, i.e. the period where we would expect little intention to dissave and little changes to the household 
composition through mortality. Specifically, we choose households headed by in individual born between 1944 and 1958. We follow these households from 1983 when they are 25 to 39 years old until 2003. By then, we observe the same cohort at an age between 45 and 59 .

We employ two measures for the contribution of the individual pathways of wealth accumulation. First, we use absolute wealth growth as derived above. This allows a comparison of the orders of magnitude across income quartiles. To relate the absolute wealth growth to the respective initial wealth, we additionally calculate growth rates. Specifically, we relate the absolute growth by the individual components $i$ over the following $t$ years to total initial wealth for each cohort-quartile-age cell. Finally, we annualize the growth rates and report compound annual growth rates contributed by the individual drivers.

$$
C A G R_{c y a}^{i}=\left(\left(1+\Delta a_{c y a}^{i} / a_{c y a}\right)^{1 / t}-1\right) * 100
$$

The key finding from our analysis is certainly, that wealth growth in Germany over the past 20 years was mainly driven by savings whereas passive savings have actually been negative (see table 1). Counting all wealth drivers together, households at the top of the income distribution achieved an average annual wealth growth of 4.8 percent in real terms. Also the middle quartiles were able to improve their wealth position, although at substantially lower rates of 2 and 1 percent per year respectively. If a household was stuck at the bottom of the income distribution we project an average annual wealth loss of 1.8 percent per year. The composition of these numbers turns out to be driven by high savings, a conservative allocation of financial assets, and negative returns on real estate wealth.

\section{The effects of active savings}

Over a time span of twenty years, household from all parts of the income distribution have increased their wealth by means of active savings. This applies even to households at the bottom of the income distribution. Negative savings early in the life-cycle and when part of the cohort was already approaching retirement are overcompensated in those years where essentially the entire cohort was in their core working age. Looking at the higher income quartiles we find a clear income gradient in the contribution of savings to absolute as well as relative wealth growth. In fact, households that remained at the top, the upper middle, the lower middle and the bottom of the income distribution over this time, would have increased their wealth by 5.2, 3.1, 2.3 and 0.8 percent per year. 
Table 1: Wealth growth by source at different positions in the income distribution (in EUR 2001)

\begin{tabular}{|c|c|c|c|c|c|c|}
\hline \multirow[b]{2}{*}{ initial wealth in 1983} & \multicolumn{6}{|c|}{ wealth growth } \\
\hline & $1983-88$ & $1988-93$ & $1993-98$ & 1998-2003 & $\begin{array}{c}\text { total growth } \\
1983-2003\end{array}$ & $\begin{array}{c}\text { 20-year } \\
\text { CAGR }\end{array}$ \\
\hline $18 ' 758 €$ & \multicolumn{6}{|c|}{ Income deciles I-III } \\
\hline active savings & $-886 €$ & $2 ' 473 €$ & $3 ' 096 €$ & $-369 €$ & 4'314 € & $0.8 \%$ \\
\hline passive savings & $-1^{\prime} 974 €$ & $-2 ' 786 €$ & $-3^{\prime} 462 €$ & $-3 ' 150 €$ & $-11 ' 372 €$ & $-3.7 \%$ \\
\hline inheritances & $4 €$ & $13 €$ & $15 €$ & $87 €$ & $118 €$ & $0.0 \%$ \\
\hline total wealth growth & $-2 ' 856 €$ & $-301 €$ & $-351 €$ & $-3,432 €$ & -6 '940€ & $-1.8 \%$ \\
\hline $46^{\prime} 670 €$ & \multicolumn{6}{|c|}{ Income deciles IV-VI } \\
\hline active savings & $5 ' 150 €$ & 8'544€ & $11 ' 736 €$ & $10 ' 533 €$ & $35 ' 963 €$ & $2.3 \%$ \\
\hline passive savings & $-5^{\prime} 136 €$ & $-6 ' 084 €$ & $-5 ' 839 €$ & $-5^{\prime} 719 €$ & $-22 ' 778 €$ & $-2.6 \%$ \\
\hline inheritances & $31 €$ & $21 €$ & $17 €$ & $62 €$ & $131 €$ & $0.0 \%$ \\
\hline total wealth growth & $45 €$ & $2 ' 481 €$ & 5'914€ & $4 ' 876 €$ & $13 ' 316 €$ & $1.0 \%$ \\
\hline 66 '953€ & \multicolumn{6}{|c|}{ Income deciles VII-IX } \\
\hline active savings & $11^{\prime} 613 €$ & $18 ' 449 €$ & $22^{\prime} 487 €$ & $23 ' 592 €$ & $76 ' 142 €$ & $3.1 \%$ \\
\hline passive savings & $-7 ' 857 €$ & $-8 ' 807 €$ & $-8 ' 543 €$ & $-7 ' 820 €$ & $-33^{\prime} 027 €$ & $-2.7 \%$ \\
\hline inheritances & $209 €$ & $164 €$ & $338 €$ & $410 €$ & $1 ' 122 €$ & $0.1 \%$ \\
\hline total wealth growth & 3'966€ & 9'806€ & $14 ' 282 €$ & $16 ' 182 €$ & $44 ' 236 €$ & $2.0 \%$ \\
\hline $95 ' 220 €$ & \multicolumn{6}{|c|}{ Income decile $X$} \\
\hline active savings & 36 '916 € & $56 ' 139 €$ & $72 ' 408 €$ & $76 ' 449 €$ & $241 ' 911 €$ & $5.2 \%$ \\
\hline passive savings & $-12 ' 089 €$ & $-11 ' 313 €$ & $-9 ' 355 €$ & $-12 ' 524 €$ & $-45^{\prime} 282 €$ & $-2.5 \%$ \\
\hline inheritances & 1'865 € & $2 ' 745 €$ & $5 ' 303 €$ & 6'724€ & $16 ' 638 €$ & $0.6 \%$ \\
\hline total wealth growth & $26 ' 691 €$ & $47 ' 571 €$ & $68 ' 356 €$ & $70 ' 649 €$ & $213^{\prime} 267 €$ & $4.8 \%$ \\
\hline
\end{tabular}

Source: own calculations based on the EVS 1983-2003; Note: inheritances estimated based on cross-sectional data from the EVS 2003, all numbers calculated in real terms.

\section{The effects of passive savings}

In contrast to active savings, which plays the expected role for wealth accumulation, passive savings have in fact been dissavings in Germany. One of the reasons is the low return on real estate wealth which does not even match the inflation rate. In real terms, housing wealth has depreciated by an average annual rate of between 0.5 and 1.7 percent (see table 2). High income households' homes have seen a somewhat more favorable price development, leading to a small income gradient in real wealth depreciation.

Additional to the unfavorable housing market, credit costs have depressed the total return on assets for all income groups. The effect is especially strong at the top and at the bottom of the income distribution. The reasons, however, are different. The poor suffer especially from high rates of debit interest, as they hold more of their debt in expensive consumer credits. For the rich, the large effects of debt are due to a higher leverage of their real estate wealth. 
Table 2: Compound annual real growth rates by wealth category (1983-2003, in \%)

\begin{tabular}{|l|cccc|}
\cline { 2 - 5 } \multicolumn{1}{c|}{} & \multicolumn{4}{c|}{ Income Decile } \\
\cline { 2 - 5 } \multicolumn{1}{c|}{} & I-III & IV-VI & VII-IX & X \\
\hline financial wealth & $1.1 \%$ & $0.7 \%$ & $0.7 \%$ & $1.0 \%$ \\
housing wealth & $-1.7 \%$ & $-1.1 \%$ & $-0.8 \%$ & $-0.5 \%$ \\
debt & $-3.2 \%$ & $-2.3 \%$ & $-2.8 \%$ & $-4.1 \%$ \\
\hline
\end{tabular}

Source: own calculations based on the EVS 1983-2003

Only for financial wealth there have been positive real rates of return over the last decades. Somewhat surprisingly, we do not find the expected clear income gradient. In fact, the bottom as well as the top income quartiles have outperformed the middle class. Overall, the real returns on financial wealth as well as the differences across income groups are quite small. First of all, the asset allocation is rather uniform across the income distribution. The largest differences can be observed for direct stockholding. While the bottom income quartile held a maximum of 5.5 percent of its wealth in stocks in 1998, the same share has never exceeded 10 percent for the top income decile. The fact, that asset allocation in Germany has remained rather conservative is certainly the main reason for the overall poor performance of financial wealth.

\section{The effects of inheritances}

For the assessment of the importance of wealth transfers we rely solely on cross-sectional information about inheritances from the EVS 2003. There is also information on other transfers from private households, be we cannot distinguish alimony and other income transfers from wealth transfers. The same applies to inter-vivos transfers to other households.

The averages reported in table 1 tell only part of the story: comparing average inheritances to the wealth levels of a cohort, they seem almost negligible. Only the top income decile can be expected to receive substantial amounts of wealth. Over 20 years, inheritances augment initial wealth of the top income quartile by roughly 17 percent. Already the third quartile gains less than 2 percent of its initial average wealth by means of inheritances. While the unconditional means look rather disappointing especially for the lower half of the income distribution, Kohli et al. (2005) has shown that for those households receiving an inheritance, their relative impact on previous wealth holdings may be quite considerable.

\section{VI.4 Age-profiles in wealth accumulation by source}

To elicit age-profiles from our repeated synthetic panel data we have to take a stand with respect to time and cohort effects. As commonly known, age-, time- and cohort-effects are by 
construction perfectly collinear. Therefore, structural assumptions are inevitable. In the following, we derive the age-effects under the assumption that there are no cohort-effects, i.e., we only include time-effects in the regression. We chose time-effects over cohort effects as we expect them to play a role for both key input variables - savings and portfolio choice. Specifically, savings have experienced some fluctuations over time. For portfolio choice, we observe quite similar trends towards more securities over time for essentially all cohorts. ${ }^{26}$ One might argue, that also cohort-effects seem to play a certain role for portfolio choice but hitherto this is much less the case for savings.

\section{Age-profiles for the contribution of active savings}

Figure 14 depicts the age-effects in absolute wealth growth through active savings over the following five years. Wealth growth through active savings has the expected hump shape for essentially all income deciles. Savings increase over the first half of the life-cycle. Peak savings are reached at age 40-44 for the bottom income decile, and around age 50 for the higher income classes. Savings drop steeply around retirement age and reach a local minimum between age 60 and 70 . For the subsequent age-groups, savings increase once more. The most likely reasons for this late increase in savings are health limitations which prevent households to consume more (Börsch-Supan and Stahl, 1991), increased precautionary savings for the case of high health and long-term care expenditures (Palumbo, 1999), as well as the non-sampling of institutionalized households which can be expected to be among the strongest dissavers. The effects of differential mortality within the existing sample have been assessed by Sommer (2008a) and have been found to be small. Overall, it is evident that especially the rich do not consume the wealth they have accumulated over the life-cycle in retirement.

Looking at the levels of new wealth accumulated through active savings, we find them to be negligible for the bottom income deciles of essentially all age-groups. At certain ages, these households have negative saving rates and are thus predicted to reduce their stock of wealth. Over the entire life-cycle we estimate an average 5yr savings effect of $-1150 €$, i.e. a wealth loss of $230 €$ per year. The differences compared to the broadly based cohort which we have analyzed above are caused by negative savings among the youngest age-group and the age-groups 50 and above. Households who remain in the lower middle income quartile over their life-cycle can be expected to accumulate close to 5’000 € by means of savings over a time span of five years. The neighboring upper middle attains about double the amounts through most of the life-cycle. The

\footnotetext{
${ }^{26}$ For a detailed disaggregation of the trends in household portfolios see Sommer (2005).
} 
gap between the second and the third income quartile widens only among the youngest agegroups and around retirement. On average, the third income quartile attains real wealth gains over five years of 13 ' $120 €$ just through savings. The saving levels of the top income decile are of a different order of magnitude: their five-year savings never fall below 20'000 Euros and average out at $47^{\prime} 900$ Euros over the entire life-cycle.

Figure 14: Age-effects for 5-year wealth growth by means of active savings

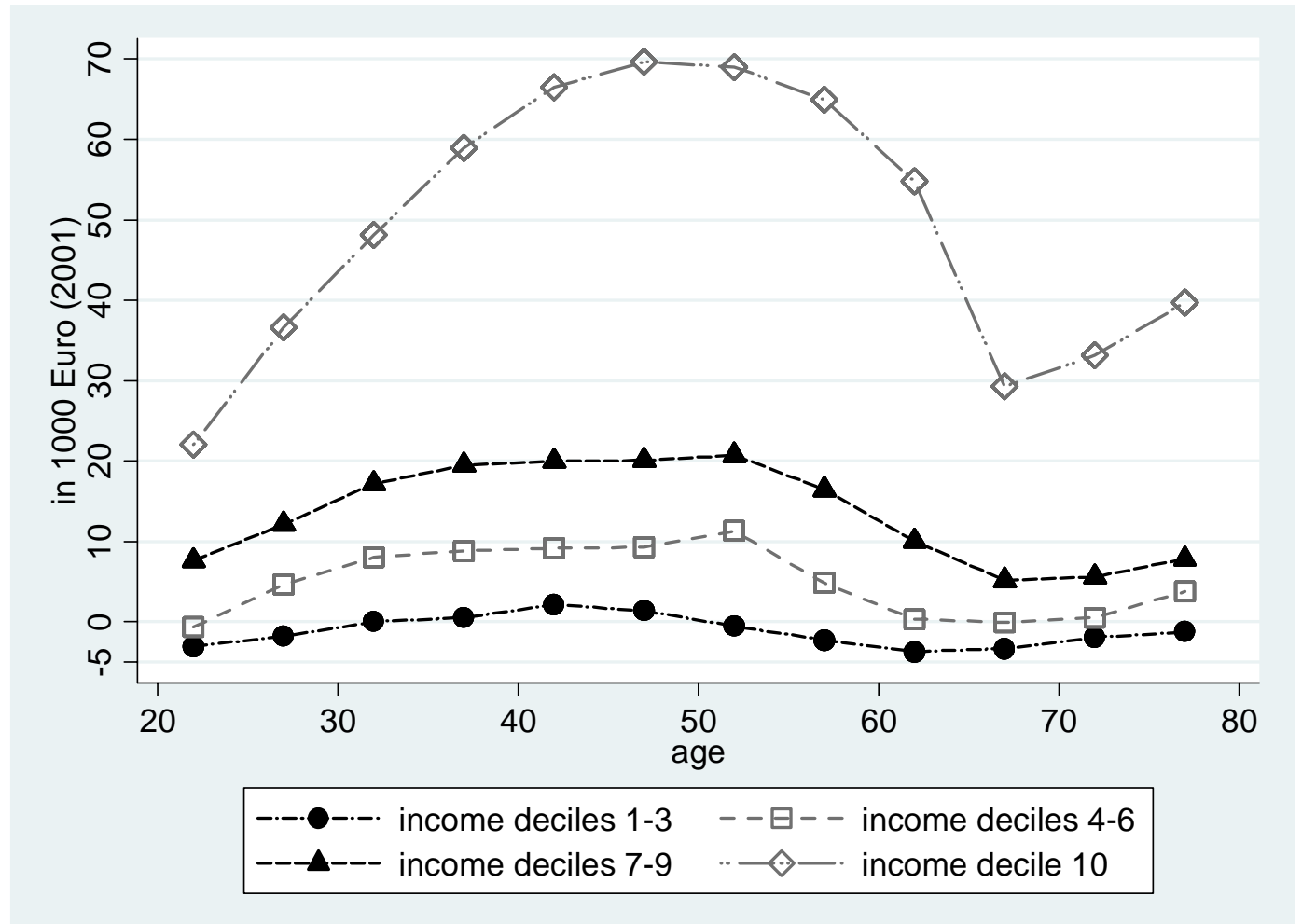

Source: own calculations based on the EVS 1983-2003

To put the above absolute figures in the context of different wealth holdings over the life-cycle and across income deciles, we now convert the above absolute wealth growth into growth rates. The growth rates always relate to the initial wealth of an income quartile at a certain age. To give an example: In real terms, the top income decile of the age-group 50-54 is projected to experience an increase in total net wealth by means of savings of 5 percent per year over the following five years based on their initial wealth at age 50-54 (figure 15).

The first feature of projected growth rates to catch the eye is certainly the clear income gradient. In all age-groups, households from higher income deciles are able to increase their wealth at a higher pace. The second finding from figure 15 is the trend towards lower growth rates as age increases. Again, this comes with little surprise, as the annual savings flows become smaller and smaller compared to the increasing stock of wealth which is accumulated over the life-cycle. Last, 
we observe substantial wealth decumulation through dissavings for the bottom half of the income distribution among the youngest age-groups. The suspicion of borrowing against higher future income levels is supported by the income and consumption data of these cohorts.

Figure 15: Age-effects for contributed growth rate through active savings

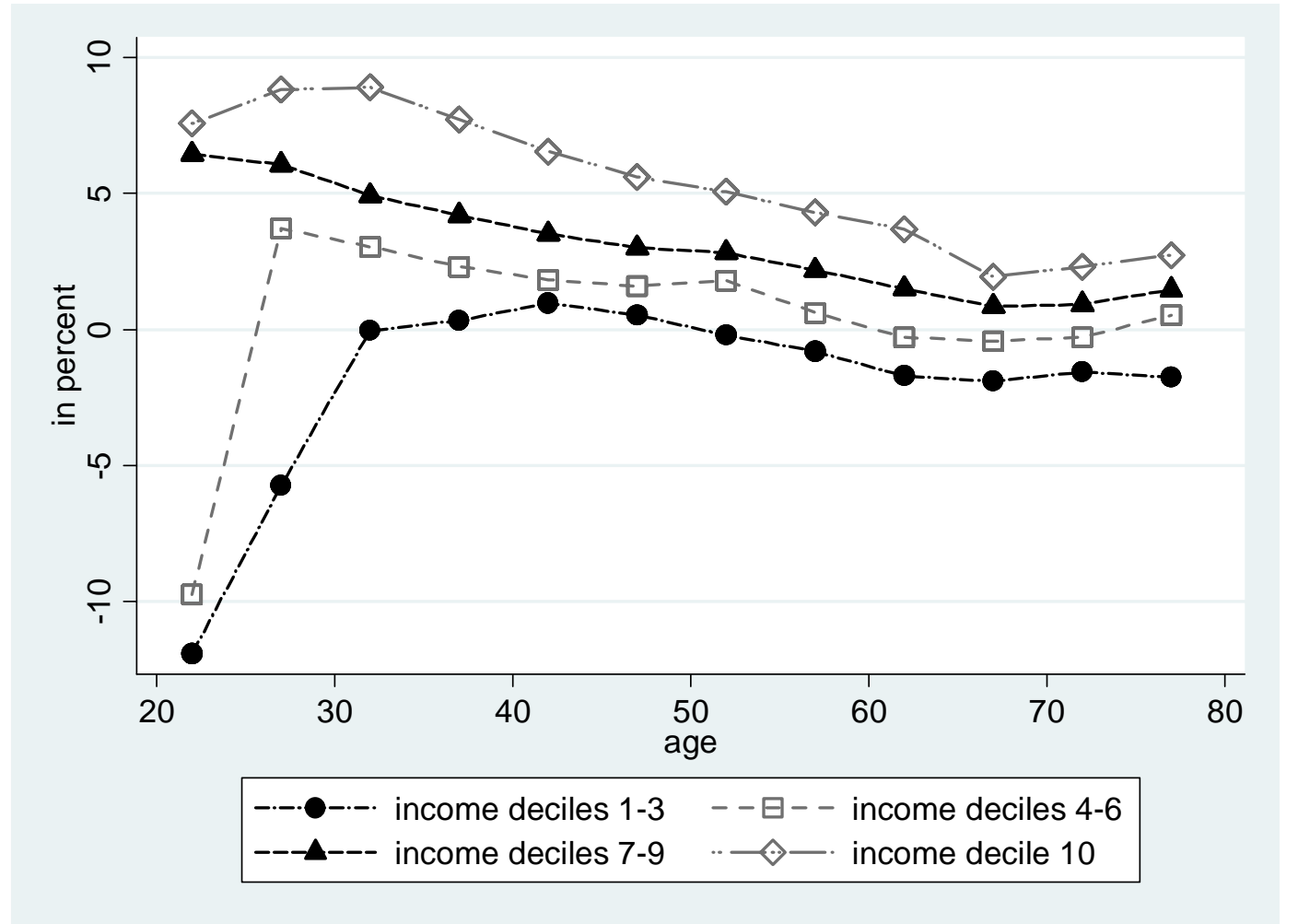

Source: own calculations based on the EVS 1983-2003

Generally, having in mind the life-cycle savings patterns in Germany, our results for active savings contain no big surprises. The key findings are certainly that the bottom 30 percent of the income distribution are unable to accumulate wealth through savings, as also documented by Börsch-Supan et al. (2006) based on the SAVE survey. Furthermore, we find the expected clear income gradient in wealth accumulation through active savings.

\section{Age-profiles for the contribution of passive savings}

Our analyses for passive savings yield essentially three key findings. First and foremost, we find considerable depreciation effects between ages 20 and 55. Essentially only the top income households are able to profit from passive savings, and only beyond retirement age. Second, the performance of poor households' portfolios is better than one might expect. Over the entire lifecycle, their returns on total wealth are level with the portfolios of middle income households. Especially at young age, their portfolios even outperform the middle class. Third and last, we find 
a clear income gradient for the performance of financial wealth for the age-groups 35 and above and a reversed income gradient for the younger age-groups.

We first look in some more detail at the u-shaped age-profile of projected passive savings. Throughout the entire working life, we observe only wealth depreciation which peaks in absolute terms around age 40 (see figure 16) and somewhat earlier at age 30-35 when looking at growth rates (see figure 17). The key to understanding the negative and u-shaped age-profile are mortgages. That is, depreciation effects play an increasing role among those age-groups with large numbers of credit-financed home owners. As the outstanding debt is repaid towards retirement, the depreciation effects decline correspondingly. In fact, wealth losses become negligible around age 60 and remain so for the remainder of the life-cycle.

Figure 16: Age-effects for wealth growth by passive savings

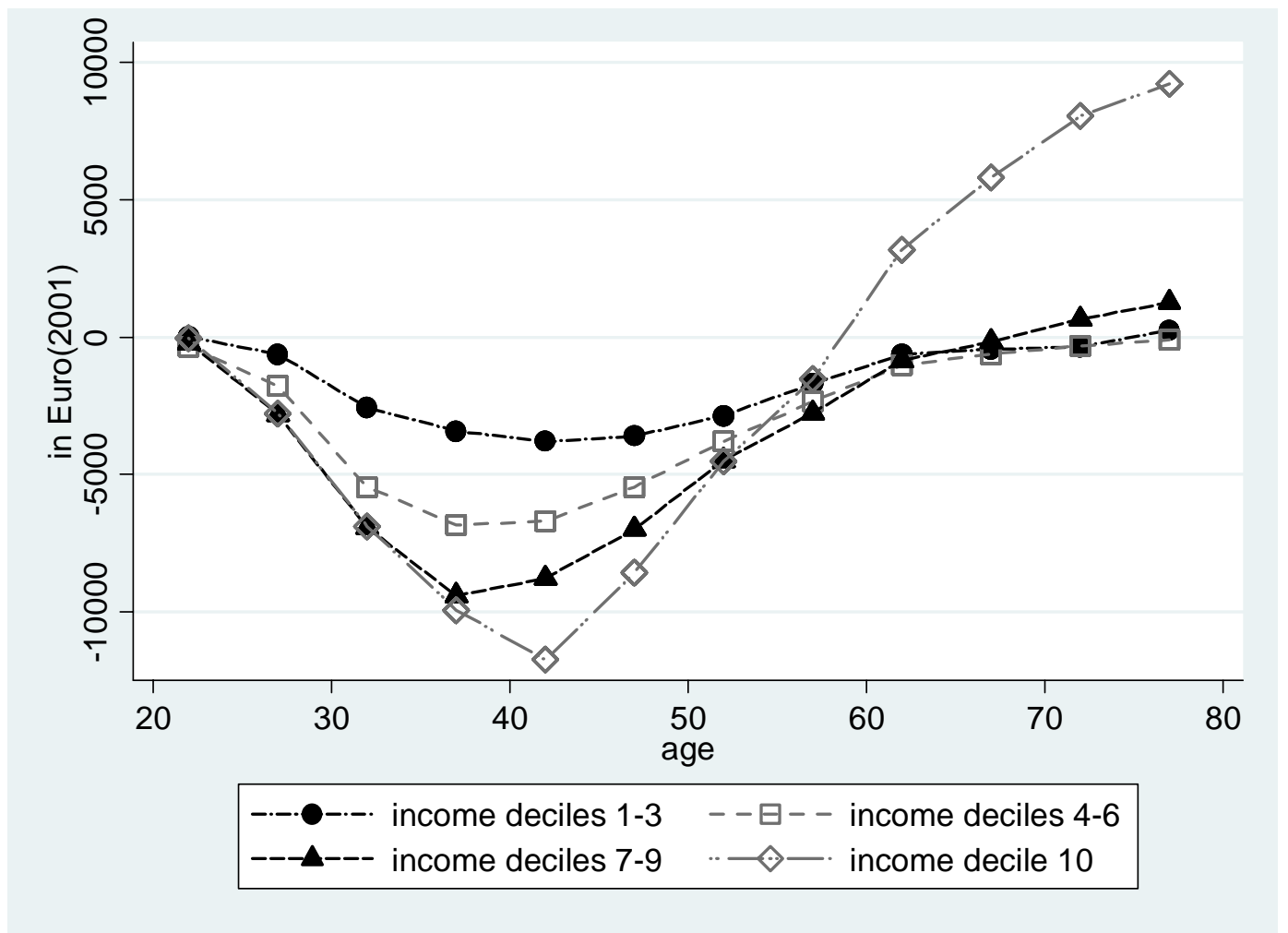

Source: own calculations based on the EVS 1983-2003

Next, there are the low overall returns from passive savings. We have already highlighted the reasons above in the context of the wide cohort. Apart from the debt effects, the poor portfolio performance of households' investments is largely due to a conservative allocation of financial assets as well as the negative real returns on housing wealth. It turns out, that the differences across quartiles are rather low throughout the entire life-cycle. The margin between the highest and the lowest projected returns ranges from 0.3 to 0.9 percentage points. For most age-groups, 
the top income decile also attains the highest return on assets. The third and the second quartile follow in the expected order at a certain distance. The main surprise in returns from passive savings concerns the performance of low income households' portfolios. Over all age-groups, they never have the worst projected performance. Furthermore, the bottom income quartile outperforms the middle income quartiles for a considerable number of age-groups. Before coming back to the surprisingly good performance of the portfolios of young low income households, we focus on passive savings from financial wealth. This seems especially worthwhile given the overall predominance of credit-financed homes for the above results.

Figure 17: Age-effects for contributed growth rate through passive savings

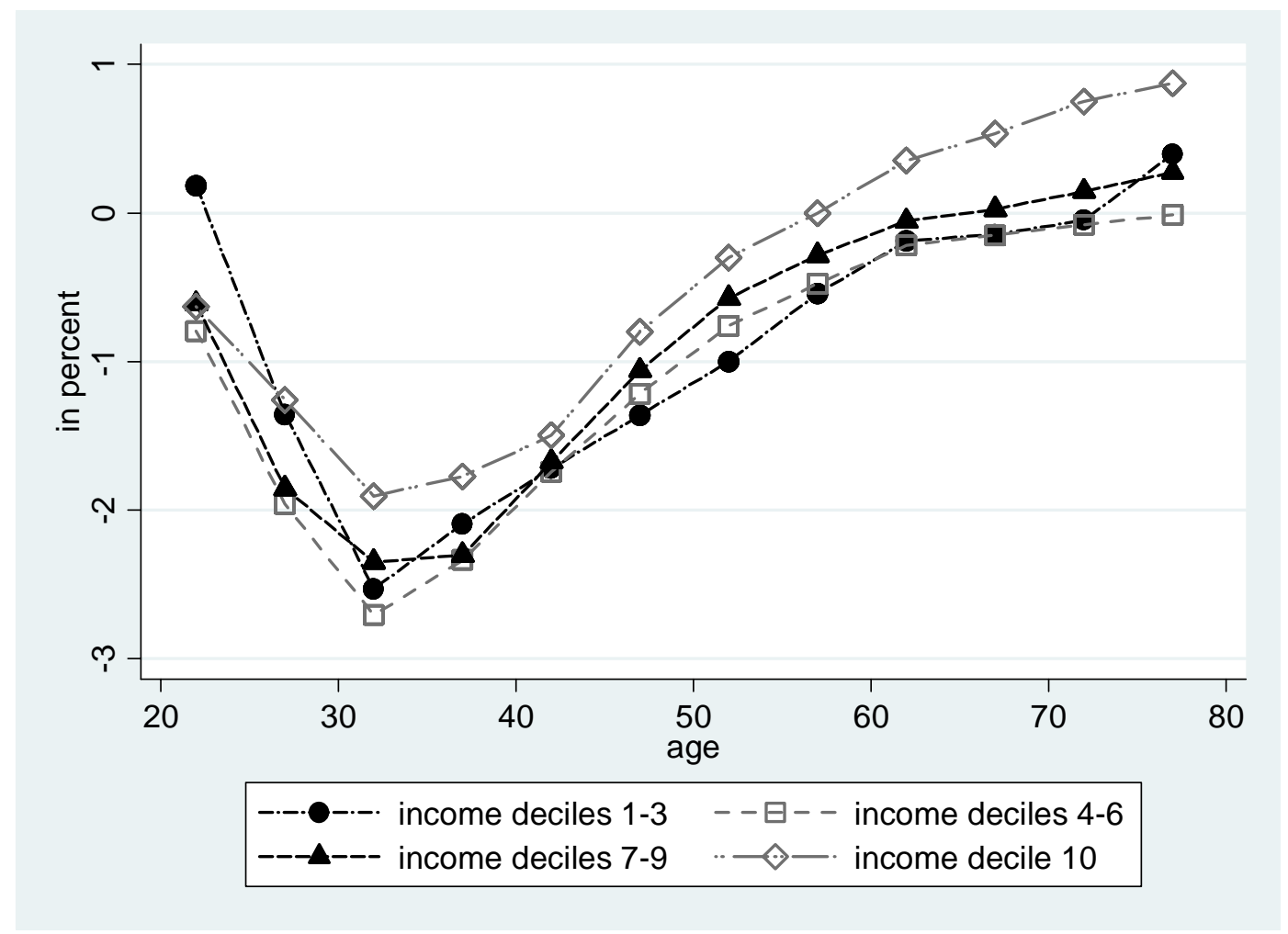

Source: own calculations based on the EVS 1983-2003

\section{Age-profiles for the contribution of passive savings from financial wealth}

The estimated age-pattern for projected growth rates in financial wealth are depicted in figure 18. Financial wealth contributes positive wealth growth for all ages and income groups. The actual real rates of return vary between 0.7 and 2.2 percent. The life-cycle pattern is essentially split in two parts. Among households below age 30, we observe an inverse income gradient and the dispersion across income quartiles is comparatively large at a margin of 120 basis points. Furthermore, it is here that we observe the highest returns. For the later age-groups, we observe 
essentially flat life-cycle profiles. Real returns are highest for the top income decile at roughly 1.11.2 percent per year. The lower income groups attain a real return between 0.7 and 0.9 percent. The reasons for these low portfolio returns are the ongoing popularity of safe assets like savings accounts and building society savings contracts among German households. ${ }^{27}$

Figure 18: Age-effects for contributed growth rate through financial wealth appreciation

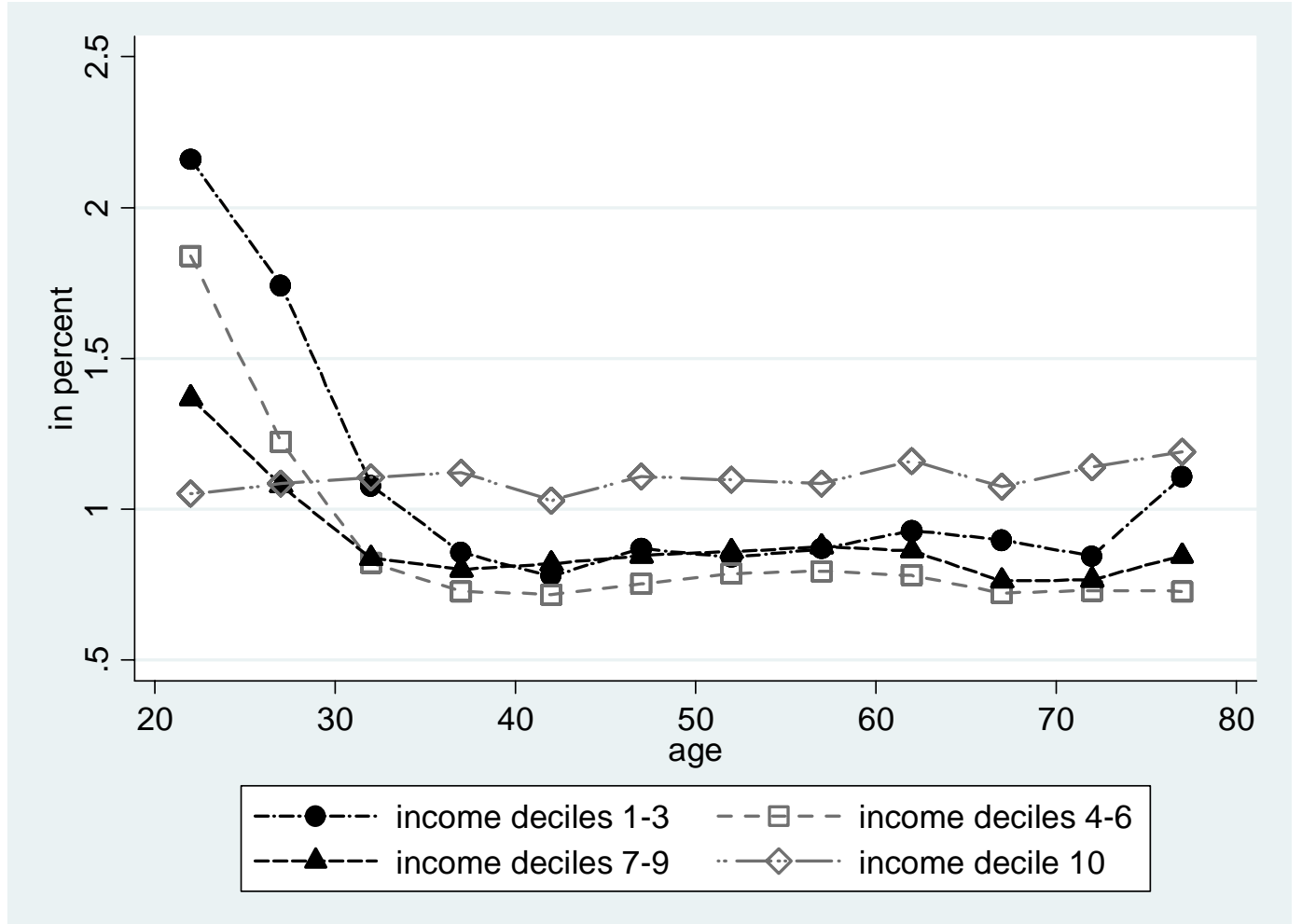

Source: own calculations based on the EVS 1983-2003

Let us come back to the remarkably good performance of the lower income quartiles among the young. One might speculate that the favorable asset allocation is driven by student households which expect high income growth in the future and therefore reduce their investment in safe but low return assets in favor of securities. Furthermore, we would expect these households to have good knowledge about financial markets and therefore choose a more attractive long run portfolio allocation. Looking at the distribution of educational attainments across income groups supports the above speculation. For a solid understanding of the investment behavior of young low income households we would require panel data though.

\footnotetext{
${ }^{27}$ For a more detailed description of trends in German household portfolios see Sommer (2005).
} 


\section{Cross-sectional age-profiles for the contribution of inheritances}

As mentioned above, it is impossible in most EVS cross-sections to distinguish wealth transfers from income transfers like e.g. alimony payments. Fortunately, the EVS 2003 allows us to separate inheritances from other transfers. In the following, we present results for a crosssectional distribution of received inheritances over age. Specifically, figure 19 depicts the averages of actual inheritances by income quartiles. The immense fluctuations indicate the difficulties involved in the measurement of such extremely rare events. ${ }^{28}$ Although the differences between the bottom income deciles are not significant for the majority of age-groups, the results suggest a certain income gradient in received inheritances.

Figure 19: Cross-sectional age-profile for average inheritances by income quartile

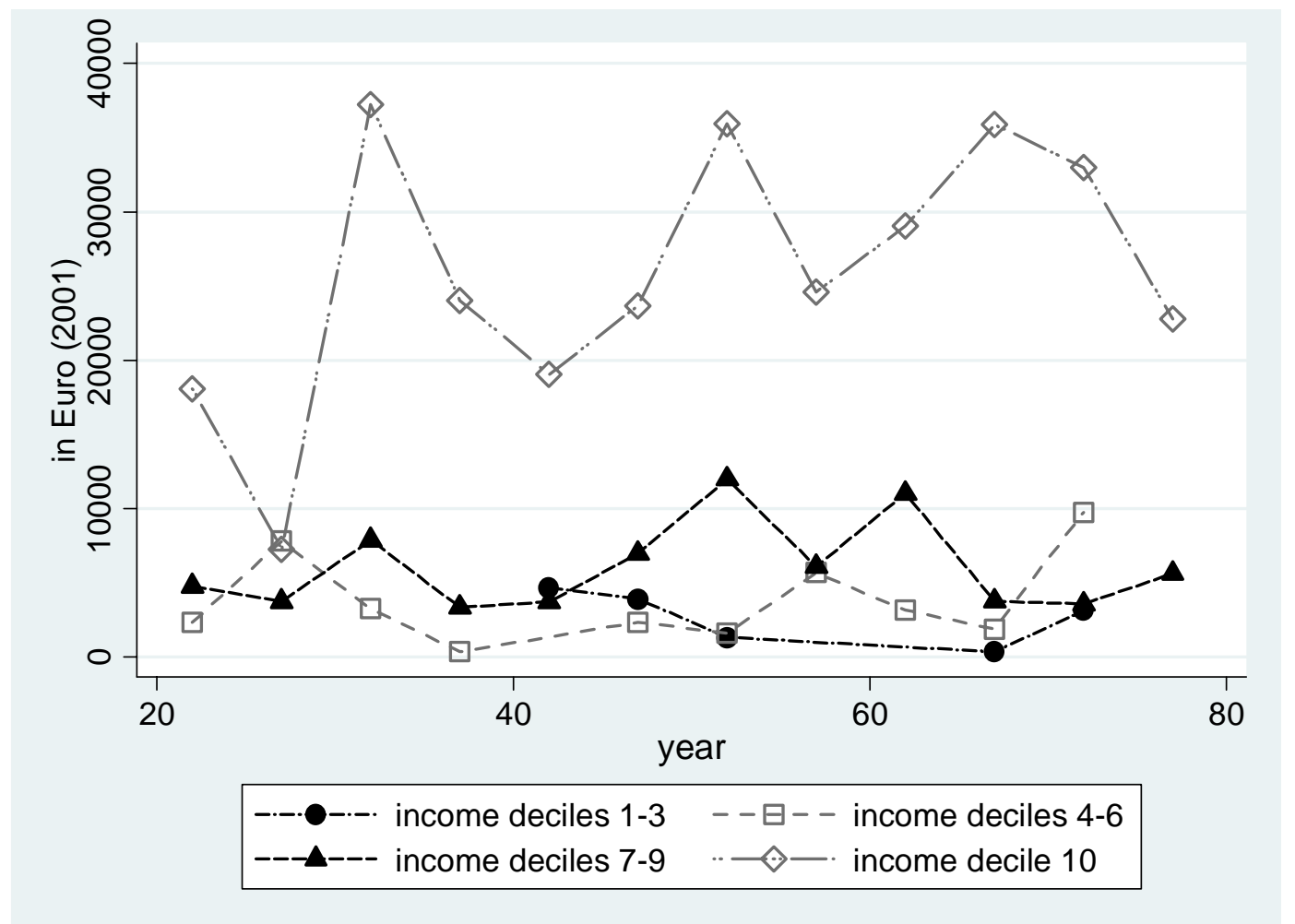

Source: own calculations based on the EVS 2003

We abstain from interpreting the age-pattern given the small number of observations at the bottom of the income distribution and the high degree of noise in the data. Table 3 therefore discards the context of age and focuses on the absolute and relative importance of inheritances for the different income quartiles at all ages. We find higher income households to expect substantially higher inheritances than households at the bottom of the income distribution. The

\footnotetext{
${ }^{28}$ We dropped one extreme case for the bottom income quartile for the estimation.
} 
stronger income gradient for the unconditional averages compared to the average actual inheritances implies that the rich are also considerably more likely to receive an inheritance in the first place.

Table 3: Absolute and relative impact of bequests on wealth holdings by income quartile

\begin{tabular}{|l|r|r|r|r|}
\cline { 2 - 5 } \multicolumn{1}{c|}{} & \multicolumn{4}{c|}{ income decile } \\
\cline { 2 - 5 } \multicolumn{1}{c|}{} & \multicolumn{1}{c|}{$1-3$} & \multicolumn{1}{c|}{$4-6$} & \multicolumn{1}{c|}{$7-9$} & \multicolumn{1}{c|}{10} \\
\hline average annual (uncond.) bequests & $1.90 €$ & $8.94 €$ & $67.22 €$ & $945.52 €$ \\
\hline levels & $0.03 \%$ & $0.03 \%$ & $0.17 \%$ & $0.74 \%$ \\
\hline average implied wealth growth & & & \\
\hline average annual actual bequests & $51.4 \%$ & $10.6 \%$ & $17.1 \%$ & $21.5 \%$ \\
\hline levels &
\end{tabular}

Source: own calculations based on the EVS 2003

Putting these numbers in relation to wealth holdings, we arrive at similar results as Kohli et al. (2005) and Westerheide (2004). Specifically, the actual incidence of inheritances has a much stronger impact on recipients at the bottom of the income distribution than for their richer counterparts. In fact, inheritances boost total wealth among households from the bottom income quartile by an average of 51.4 percent. The corresponding effects for the next higher income classes range only between 10.6 and 21.5 percent.

\section{Issues and limitations of the above analysis}

In the absence of panel data, any life-cycle analysis will be based on less-than-ideal solutions like a synthetic panel. Especially the assumption that cohorts remain homogeneous over time is a questionable one. Above, we have already discussed the possible effects of changes to the household head and of differential mortality which we consider a minor concern for our analysis. However, the interpretation of the above results becomes delicate through our stratification of cohorts by income. Specifically, connecting the projections of equal income quartiles over age for a life-cycle interpretation is dangerous given the degree of mobility in the income distribution. That is, a considerable number of households will switch between different income quartiles over their life-cycle. An example are university graduates, who tend to enter the labor market several years later than the remaining population. Thus, these households will start from a rather low relative income position. Their subsequent life-cycle earnings path is steeper so that they will move up the income distribution. A similar case can be made for the job market exit. E.g. selfemployed households who do not receive a public pension may drop from an above average income level to rather low post-retirement incomes. Thus, our results can only be interpreted as 
short run projections of average wealth growth of households at a certain age and a certain income position. If we nevertheless follow income quartiles over age, we will tend to underestimate wealth accumulation of households starting at the bottom of the income distribution and overestimate wealth accumulation at the top.

The second important limitation of our analysis is connected to the assumptions involved in the projections. As our use of common average real returns is aimed at the estimation of stylized lifecycle pattern of wealth accumulation, these projections are unqualified to replicate the actual year-to-year changes in wealth levels. Furthermore, we ignore important aspects of inequality within and between income quartiles. In fact, we most certainly underestimate the dispersion between income quartiles as we ignore a possible income gradient in asset returns due to different credit conditions and differences in financial literacy.

Overall, our results certainly depend strongly on a small number of factors: The high saving rates which we observe for German households at all age-groups, their rather conservative asset allocation and the poor returns especially on housing wealth over the past decades. Consequently, the relative importance of active and passive savings can only be generalized to countries with similar characteristics. Vice versa, we would expect quite different results e.g. for the United States where real estate prices have evolved more favorably, where stocks are highly popular in household portfolios, and where saving rates are considerably lower. However, the case of Germany nicely illustrates the precarious wealth shrinkage in the case of leveraged real estate ownership with low or real estate returns. Only the high saving rates of German households have ultimately allowed a growth of net total wealth over the past decades. 


\section{Conclusion}

In this paper, we document the trends in inequality for Germany over the past twenty five years based on data from the German Income and Expenditure Survey (EVS). First of all, the results are prepared to provide a benchmark for future macroeconomic modeling which increasingly incorporates various forms of heterogeneity on behalf of the household sector. Against the background of demographic change, OLG models play a particularly important role in macroeconomic modeling. Thus, we take a great interest in the trends in inequality over the lifecycle to provide these models with benchmarks for the calibration of life-cycle behavior. At the same time, our results can be employed to assess the prospects for inequality in an aging society. Like in most important economies, income, consumption and wealth inequality have been on the rise in Germany over the past decades. For international standards the growth in inequality has been comparatively moderate in Germany, but so have been the growth rates in the corresponding levels.

Consumption inequality has been almost constant over the last decades. Important drivers of inequality have been the trend towards smaller households and the reunification. Correcting for household size and other observable household characteristics, the residual level of inequality has even declined slightly. Over the life-cycle we find a clear upward trend in consumption inequality. The prospects for consumption inequality are therefore dependent on two countervailing factors. The retirement of the baby boom generation will shift a large cohort away from the high preretirement consumption levels. At the same time, consumption inequality within this important cohort can be expected to increase in upcoming years.

For income inequality, we observe a distinct upward trend in inequality which has only leveled off between 1998 and 2003. The connections between income and consumption inequality seem to be sufficiently close to generate almost identical trends in the parts of inequality which can be explained by household characteristics. The main difference compared to income is the increasing rather than decreasing level of unexplained income dispersion. Looking at the results for income inequality over the life-cycle we find them to be somewhat sensitive to the chosen econometric specification. Only two aspects emerge pretty clearly: before age 30 and between age 50 and 60, income inequality rises more strongly than for the remainder of the life-cycle. Furthermore the raw data suggests rather strong positive cohort effects between the cohorts born in 1930 and 1950. We observe them in the middle of their life-cycles, where the individual age trajectories in income inequality have shifted pretty strongly towards higher levels of inequality.

Our results for wealth inequality differ considerably depending on whether we focus on financial wealth or total wealth. It turns out that financial wealth inequality has grown double as fast as 
inequality in total wealth. Once again, a favorable development of inequality coincides with low growth rates - in this case for real estate wealth. Compared to income and consumption inequality, household characteristics can explain only a tiny part of the cross-sectional variation in wealth inequality. Looking at the life-cycle pattern of wealth inequality, the results once again depend strongly on the inequality measure and the econometric specification we choose. A closer look at the raw data confirms the different results but hints also at a possible explanation. Specifically, we find rather flat age-profiles and only little cohort differences based on the Gini coefficient, which is not very sensitive towards changes at the extremes of the distribution. The variance is much more sensitive to changes in the tails of the distribution and exhibits stronger cohort differences and upward sloping age-trajectories. This indicates that most of the grown inequality has happened at the extremes of the wealth distribution.

We conclude this paper by supplementing the above life-cycle effects in inequality with a more detailed analysis of the drivers behind life-cycle wealth accumulation in Germany. To do so, we simulate wealth growth of households at different age-groups and with different positions in the income distribution by projecting their wealth growth based on active savings and their portfolio choice derived from our synthetic panel data. To arrive at stylized pattern of wealth accumulation, we apply average real returns to the observe portfolio allocation. In a second step, we elicit age-trajectories based on a simple regression.

For active savings, we observe a strong income gradient. Except for the bottom income quartile which is largely unable to save, all households receive their strongest wealth growth through active savings. Total passive savings turn out to be dissavings over the entire working age and for all income groups. The reason are mortgages which are taken up with the purchase of a home and only paid back slowly towards retirement age. The actual real returns on housing wealth have been negative in Germany over the past decades. Given the large share of total wealth invested in the privately owned home the positive returns on financial wealth do not suffice to compensate the negative effects from leveraged real estate wealth. Overall, the real returns on financial wealth are rather poor and range between 1.3 percent for the top income decile and 0.7 percent for the lower income groups. The underlying reason is the asset allocation of German households which still holds fast to saving accounts and is cautious with respect to a higher exposure to the stock market.

For inheritances we unfortunately only have cross-sectional data available. Based on the EVS 2003 we show that the probability of receiving a bequest as well as the absolute amounts of wealth received increase strongly in income. The actual incidence of an inheritance has a much stronger impact on wealth growth for low income households though. These results are in line with the findings of Kohli et al. (2005) and Westerheide (2004). Yet over all households, the 
importance of average inheritances for wealth growth turns out to be small. Only for the top income decile, the impact of inheritances is noticeable also for average wealth growth.

Overall, our results on the relative importance of savings, portfolio returns and inheritances for wealth growth are certainly specific to the case of Germany. Especially for countries with lower saving rates and a less conservative asset allocation like most Anglo-American countries, we would expect quite different results. However, the unfortunate German case of negative real returns on real estate accentuates the risks involved in leveraged investments. Only the high saving rates have ultimately led to a growing stock of household wealth in Germany over the past decades. 


\section{References}

AMERIKS, J., AND S. P. ZELDES (2001): “How do household portfolios vary with age?,” unpublished manuscript, Columbia University.

Ammermüller, A., AND A. Weber (2003): "Education and wage inequality in Germany - a review of the empirical literature," ZEW discussion paper, 03-29.

Atkinson, A.B., L. Rainwater, And T. Smeeding (1995): "Income distribution in OECDcountries," OECD Social policy studies, 18.

BACH, S., G. CORnEO, AND V. STEINER (2007): "From bottom to top: the entire distribution of market income in Germany, 1992-2001,” DIW discussion paper, 683.

BECKER, I. (2006): "Effektive Bruttostundenlöhne in Deutschland. Eine Verteilungsanalyse unter Aspekten der Leistungsgerechtigkeit und besonderer Berücksichtigung des Niedriglohnsegments,” Arbeitspapier Nr. 2 des Projekts „Soziale Gerechtigkeit“, Fachbereich Wirtschaftswissenschaften der Universität Frankfurt am Main.

Becker, I., J.R. Frick, M.M. Grabka, R. Hauser, P.Krause, and G. Wagner (2002): “A comparison of the main household income surveys for Germany: EVS and SOEP," In: R. Hauser and I. Becker (eds.) Reporting on income distribution and poverty. Perspectives from a German and European point of view. Springer Verlag. Berlin and Heidelberg, 55-90.

BECKER, I., AND R. HAUSER (2003): Anatomie der Einkommensverteilung. Ergebnisse der Einkommens- und Verbrauchsstichproben 1969-1998. Berlin

BIEWEN, M. (2000): “Income inequality in Germany during the 1980s and 1990s," Review of income and wealth, 46 (1), 1-19.

BIRD, E.J., J. SCHWARZE, AND G.G. WAGNER (1994): "Wage effects of the move towards free markets in East Germany,” Industrial and labor relations review, 47, 390-400. 
BÖRsCH-Supan, A., A. ReIL-Held, D. SCHunK (2006): “Das Sparverhalten deutscher Haushalte: Erste Erfahrungen mit der Riester-Rente," MEA discussion paper, 114-2006.

BÖRsCh-Supan, A., AND K. STAhl (1991): "Life-Cycle Savings and Consumption Constraints," Journal of Population Economics, 4, 233-255.

BourguignON, F. (1979): "Decomposable income inequality measures," Econometrica, 47, 901920.

Brugiavini, A. AND G. Weber (2001): "Household savings: concepts and measurement," in: International comparisons of household saving. Academic Press, New York.

Burkhauser, R.V., T. Smeeding, And J. Merz (1994): "Relative inequality and poverty in Germany and the United States using alternative equivalence scales,” Cross-National Studies in Aging Program Project Paper No. 18. Center for Policy Research, The Maxwell School, Syracuse University, Suracuse, NY.

CARROL, C.D. AND A.A. SAMWICK (1998): “How important is precautionary saving?," The review of economics and statistics, 80 (3), 410-419.

Coudouel, A., J.S. HentSCHEL, AND Q.T. WOdON (2002): "Poverty measurement and analysis," PRSP Sourcebook, Worldbank, Washington D.C.

Deaton, A. And C. Paxson (1994): "Savings, growth and aging in Taiwan," in: Studies in the economics of aging, ed. by D. Wise. Chicago University Press. Chicago.

EDLUND, L., AND W. KopCZUK (2007): “Women, wealth and mobility," NBER working paper, 13162.

FRANZ, W., AND V. STEINER (2000): "Wages in the East German transition process - facts and explanations," German economic review, 1 (2), 241-270. 
HAUSER, R. (2003): "The development of the distribution of income and wealth in Germany - an overview," In: R. Hauser and I. Becker (eds.) Reporting on income distribution and poverty. Perspectives from a German and European point of view. Springer Verlag. Berlin and Heidelberg, 7-28.

HAuser, R. (2006): "Vierzig Jahre EVS - Basis für Trendanalysen zum Wandel der Konsumstrukturen und der Einkommens- und Vermögensverteilung," Vortrag im Rahmen der 1. Nutzerkonferenz EVS.

HAUSER, R., AND H. STEIN (2001): “Die Vermögensverteilung im vereinigten Deutschland,” Reihe Stiftung der privaten Haushalte, Bd. 37. Frankfurt, New York.

HENDRICKS, L. (2007): "How important is discount rate heterogeneity for wealth inequality?," Journal of Economic Dynamics and Control, 31, 3042-3068.

Huggett, M., G. Ventura, AND A. YARON (2006): "Human capital and earnings distribution dynamics?," Journal of Monetary Economics, 53, 265-290.

Huggett, M., G. Ventura, And A. Yaron (2007): “Sources of lifetime inequality?,” Working paper.

FUCHS-SCHÜNDELN, N., D. KRÜGER, AND M. SOMMER (2008): “Cross-sectional facts for macroeconomists: the case of Germany," mimeo.

Gernandt, J., AND F. Pfeiffer (2006): "Rising wage inequality in Germany," $Z E W$ discussion paper, 06-019.

GotTschalk, P., AND S. DANZiger (2005): "Inequality of wage rates, earnings, and family income in the United States, 1975-2002," Review of income and wealth, 51, 231-255.

GRONAU, R. (1976): "Leisure, home production and work - the theory of the allocation of time revisited," Journal of Political Economy, 85 (6), 1099-1124.

GustAfsSON, B., AND M. JOHANSSON (1999): "In search of smoking guns: What makes income inequality vary over time in different countries?," American Sociological Review, 64 (4), 585-605. 
Jianakoplos, N.A., AND P.L. MenChIK (1997): "Wealth Mobility?," The Review of Economics and Statistics, 79 (1), 18-31.

KEANE, M.P., AND K.I. WOLPIN (1997): “The career decisions of young men,” Journal of political Economy, 105 (3), 473-521.

KENNICKEL, A. (2002): "Demographic shifts in the distribution of wealth, 1992-1998: Evidence from the Survey of Consumer Finance," SCF working paper prepared for the $27^{\text {th }}$ general conference of the international association for research in income and wealth.

Kohl, M., H. KÜhnemund, C. Vogel, M. Gilles, J.P. Heisig, J. SCHupP, A. SCHÄFER, ANd R. HILBRICH (2005): "Zusammenhänge und Wechselwirkungen zwischen Erbschaften und Vermögensverteilung," Gutachten für das Bundesministerium für Arbeit und Soziales.

LEVY, F., AND J.R. MURNANE (1992): “U.S. earnings levels and earnings inequality: a review of recent trends and proposed explanations," Journal of Economic Literature, 15, 1333-81.

Ludwig, A., T. SCHELKLE, AND E. VOGEL (2007): "Demographic change, human capital, and endogenous growth," MEA discussion paper, 151-07.

MERZ, J. (2003): "What is missing in the EVS? A distributional analysis of high income with the merged income tax statistic for self-employed and employees," Jabrbücher für Nationalökonomie und Statistik, 223 (1), 58-90.

MOdigliani, F. AND R. BRUMBERG (1954): ““Utility analysis and the consumption function: an interpretation of cross-section data,” in Kenneth K. Kurihara, ed., Post-Keynesian Economics, New Brunswick, NJ. Rutgers University Press. 388-436.

OECD (2008): OECD Economic Outlook, No. 83.

Pudney, S. (1993): "Income and wealth inequality and the life-cycle: a non-parametric analysis for China," Journal of Applied Econometrics, 8 (3), 249-276.

SCHOLZ, J.K. (2003): „Wealth inequality and the wealth of cohorts,” University of Wisconsin. mimeo.. 
SCHWARZE, J. (1996): „How income inequality changed in Germany following reunification: an empirical analysis using decomposable inequality measures," Review of income and wealth, 42 (1), 111.

SHORROCKS, A.F. (1980): „The class of additively decomposable inequality measures,” Econometrica, 48 (3), 613-625.

SOMMER, M. (2008): "Imputation and harmonisation of income, consumption, savings and wealth data from the German income and expenditure survey," mimeo.

SOMMER, M. (2008a): "Are Germans really not dissaving at old age or are we just not seeing it," mimeo.

STECKEL, R.H., AND J. KRISHNAN (1992): „Wealth mobility in America: A view from the National Longitudinal Survey," NBER working paper, 4137.

STEINER, V., AND K. WAGNER (1998): "Relative earnings and the demand for unskilled labor in West German Manufacturing," In: S. Black (ed.) Globalization, technological change, and the welfare state. Kluver Academic Publishers. Washington D.C.

Westerheide, P. (2004): „Auswirkungen von Erbschaften und Schenkungen auf die Vermögensbildung privater Personen und Haushalte," ZEW discussion paper, 04-28. 


\section{Appendix I - graphs}

Figure A-1: Cohort analysis for the evolution of inequality in post-government income

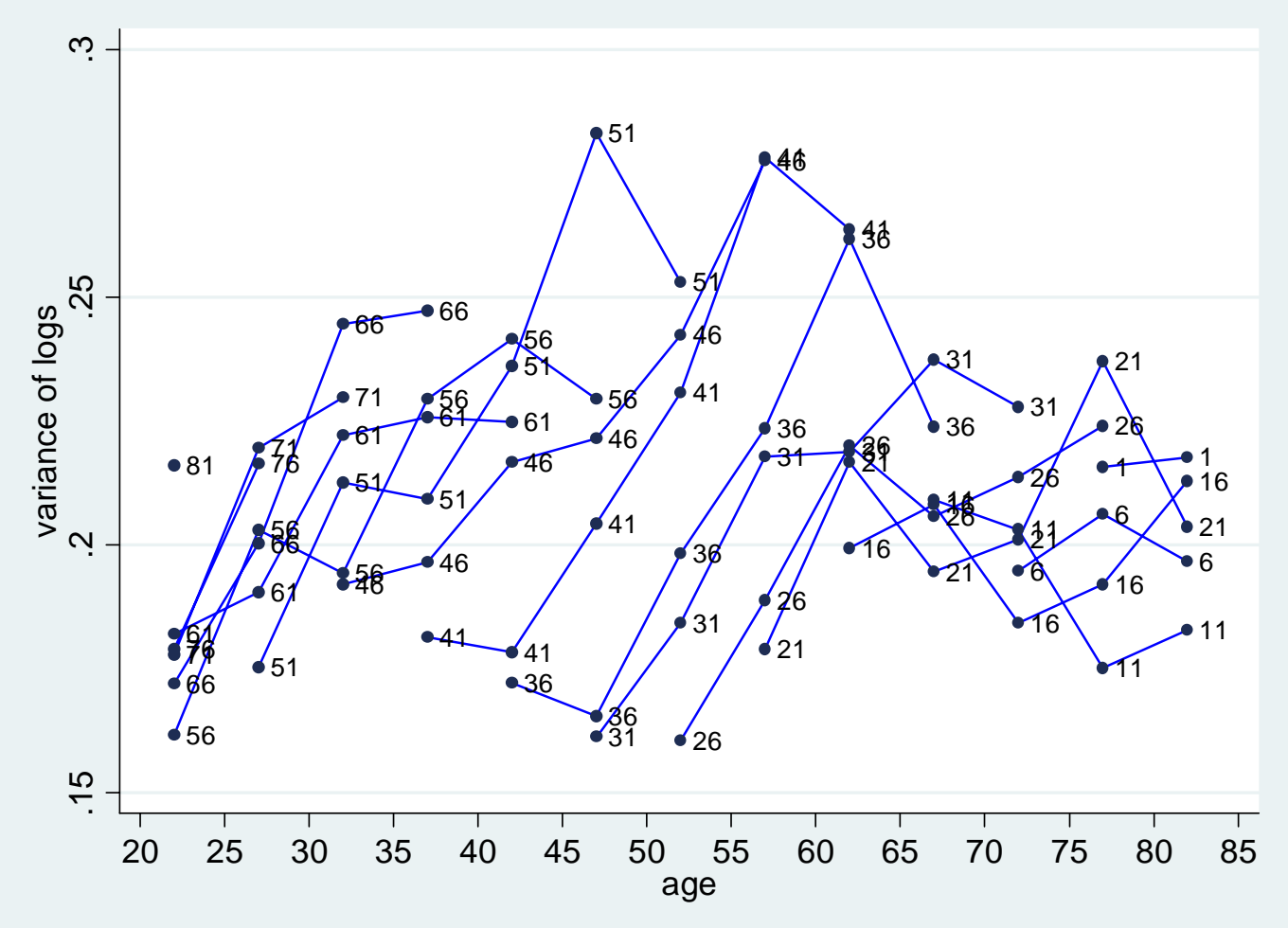

Figure A-2: Cohort analysis for the evolution of inequality in non-durable consumption

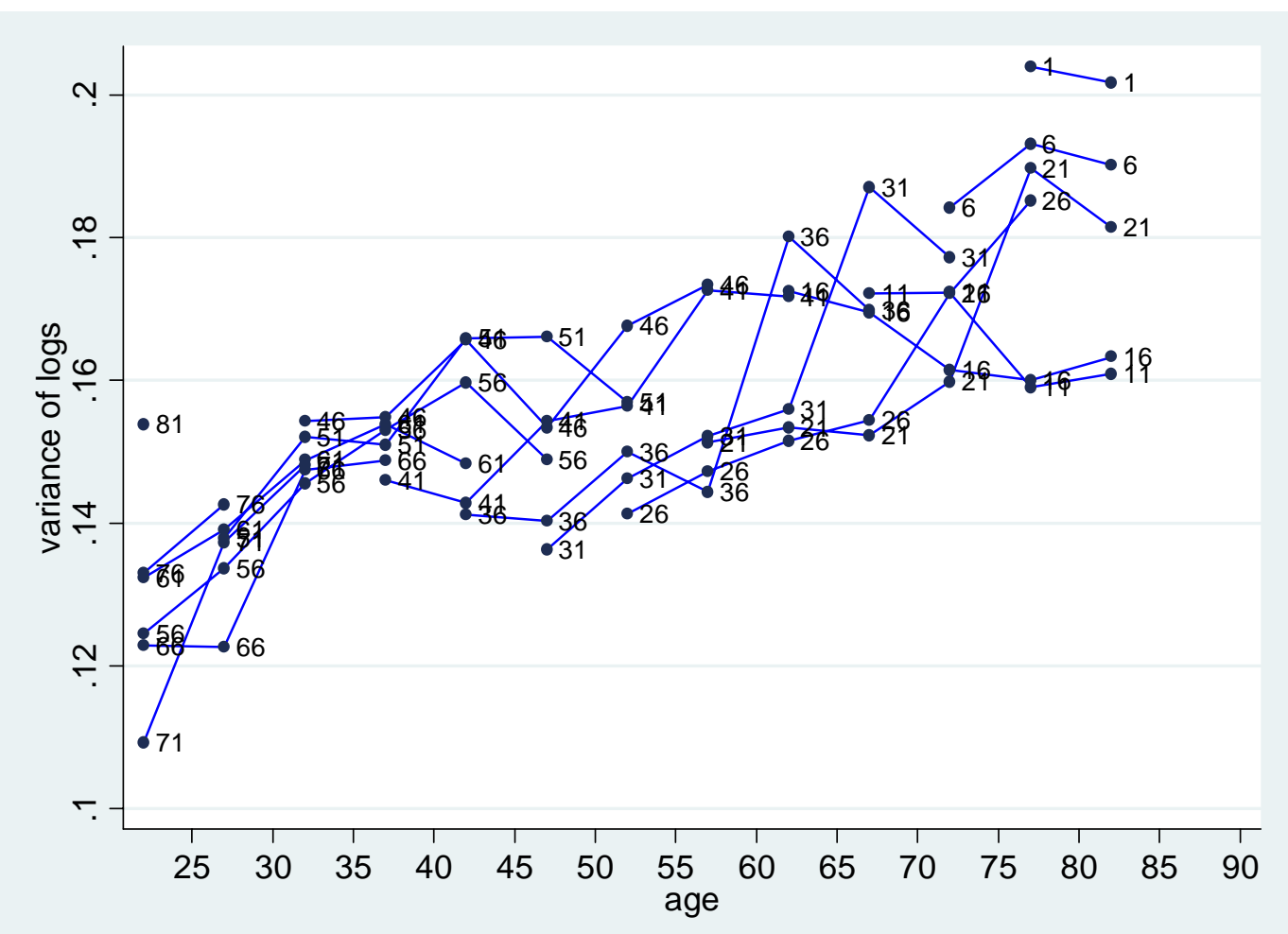


Figure A-3a: Cohort analysis for the evolution of inequality in total net wealth

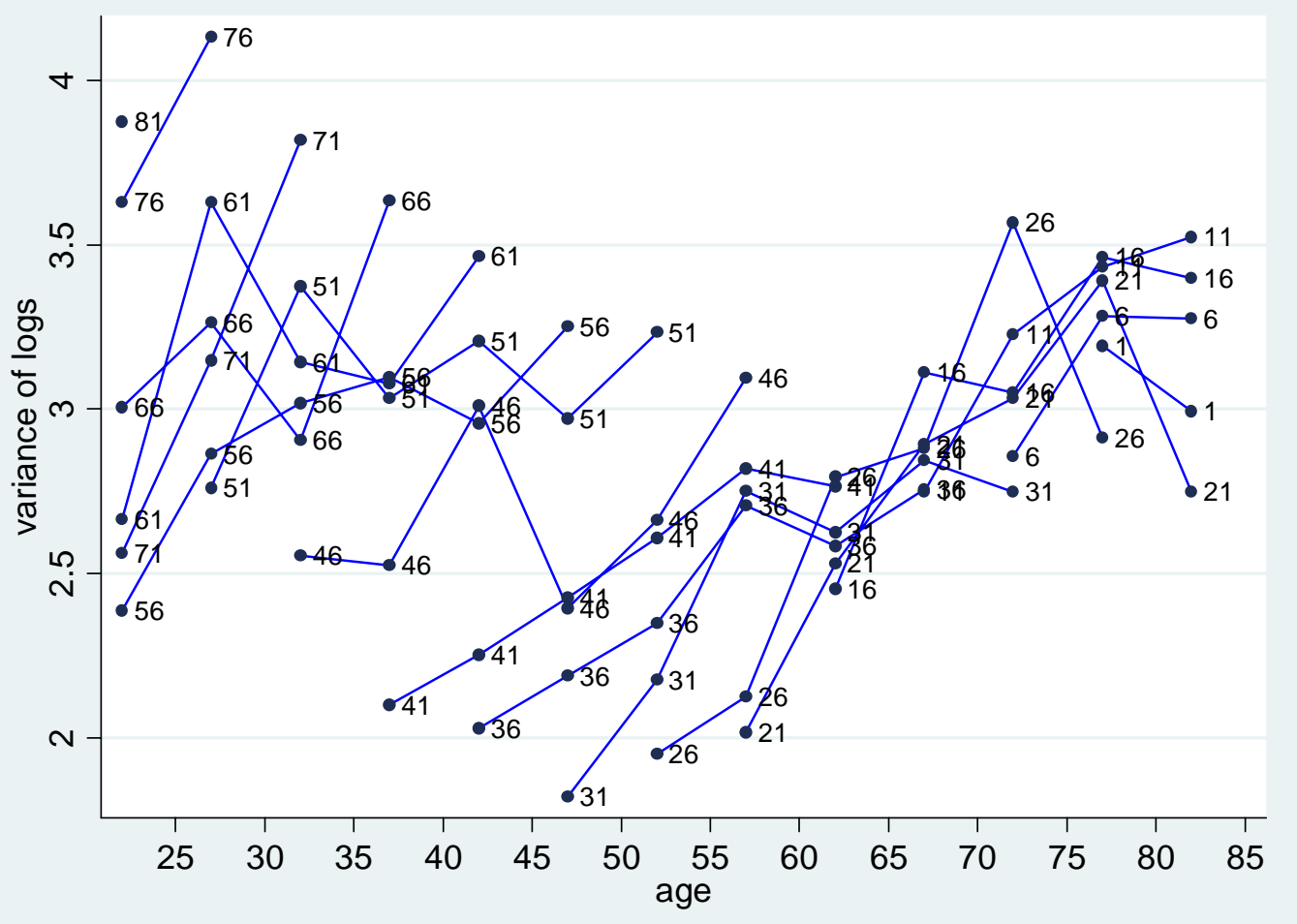

Figure A-3b: Cohort analysis for the evolution of inequality in total net wealth

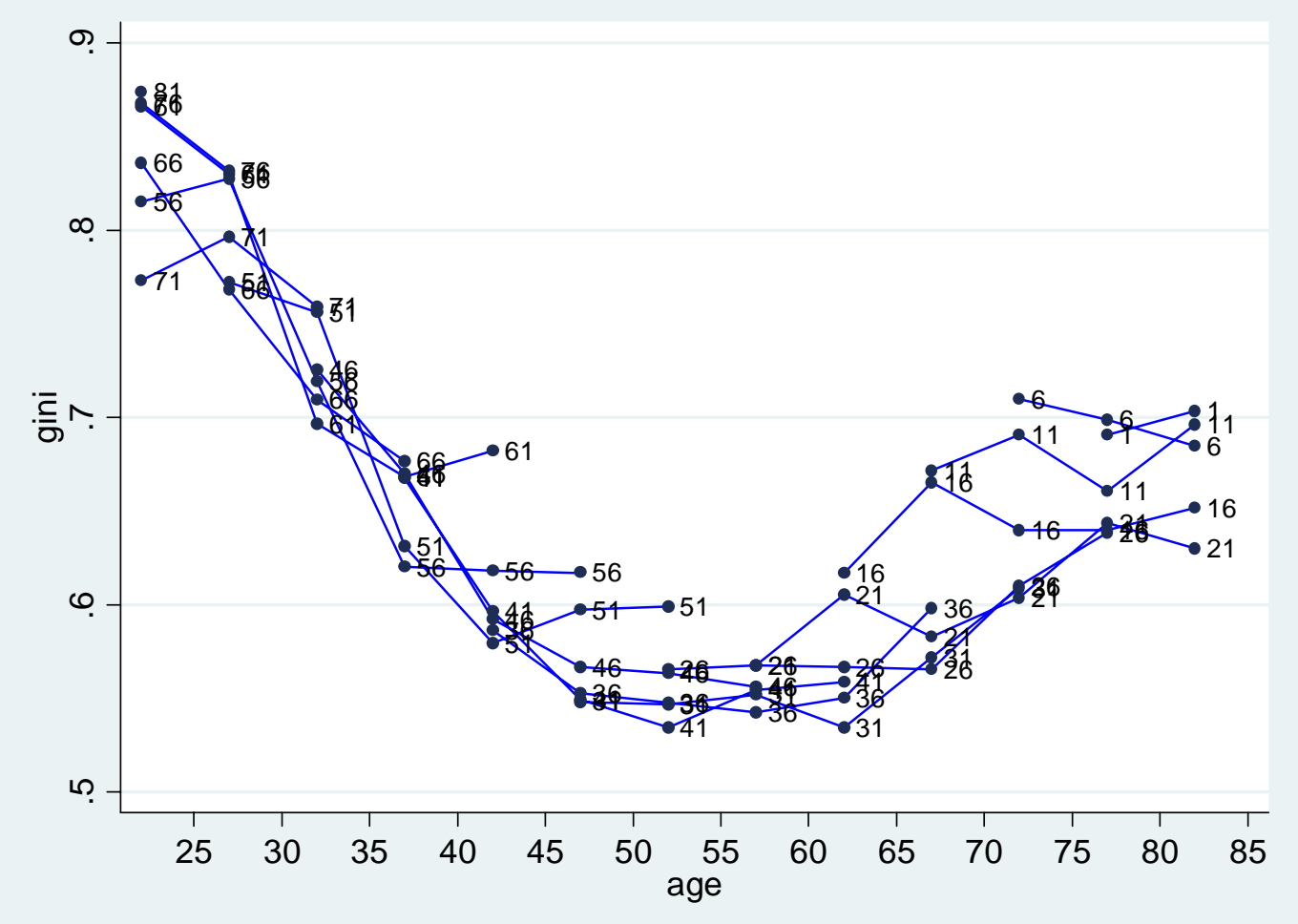




\section{Appendix II - assumptions and methodology}

In the following, we shortly describe the assumptions used for the projection of passive savings in section VI. We first tabulate the nominal rates of return and the inflation rates employed and then turn to the estimation of differential real estate returns by income quartiles.

\section{Nominal returns and inflation rates}

Table A-1 documents the nominal returns and inflation rates underlying our wealth growth projection in section six. We assume constant returns and interest rates for all cohorts at all ages. Only for real estate, we differentiate between returns in the different income deciles.

Table A-1: Assumptions for nominal returns and inflation

\begin{tabular}{|c|c|c|c|c|}
\hline & \multicolumn{4}{|c|}{ income decile } \\
\hline & $1-3$ & $4-6$ & $7-9$ & 10 \\
\hline \multicolumn{5}{|l|}{ financial wealth } \\
\hline \multirow{5}{*}{$\begin{array}{l}\text { saving accounts } \\
\text { building society saving contracts } \\
\text { stocks } \\
\text { other securities } \\
\text { life insurance }\end{array}$} & \multicolumn{4}{|c|}{$3 \%$} \\
\hline & \multicolumn{4}{|c|}{$3 \%$} \\
\hline & \multicolumn{4}{|c|}{$8.30 \%$} \\
\hline & \multicolumn{4}{|c|}{$5.95 \%$} \\
\hline & \multicolumn{4}{|c|}{$5 \%$} \\
\hline real estate & $0.87 \%$ & $1.08 \%$ & $1.27 \%$ & $1.54 \%$ \\
\hline \multicolumn{5}{|l|}{ debt } \\
\hline \multirow{2}{*}{$\begin{array}{l}\text { consumer credit, installment credit } \\
\text { mortgages }\end{array}$} & \multicolumn{4}{|c|}{$11.57 \%$} \\
\hline & \multicolumn{4}{|c|}{$7.04 \%$} \\
\hline inflation & \multicolumn{4}{|c|}{$1.90 \%$} \\
\hline
\end{tabular}

Sources: MGI, Statistisches Bundesamt, own calculations

\section{Estimating the rate of return on real estate for different income groups}

The EVS contains data on the market value of real estate wealth as well as detailed information on the primary residence. To avoid mixing price and quantity effects, we estimate prices per square meter based on the sample of households which owns only one piece of real estate. The compound annual nominal growth rates are then generated based on the median square meter prices of real estate in the respective income groups between 1988 and 2003. Figure A-4 graphically illustrates the actual development of the square meter prices used for the above calculations in Euros (2001). 
Figure A-4: Development of median square meter prices (in real terms)

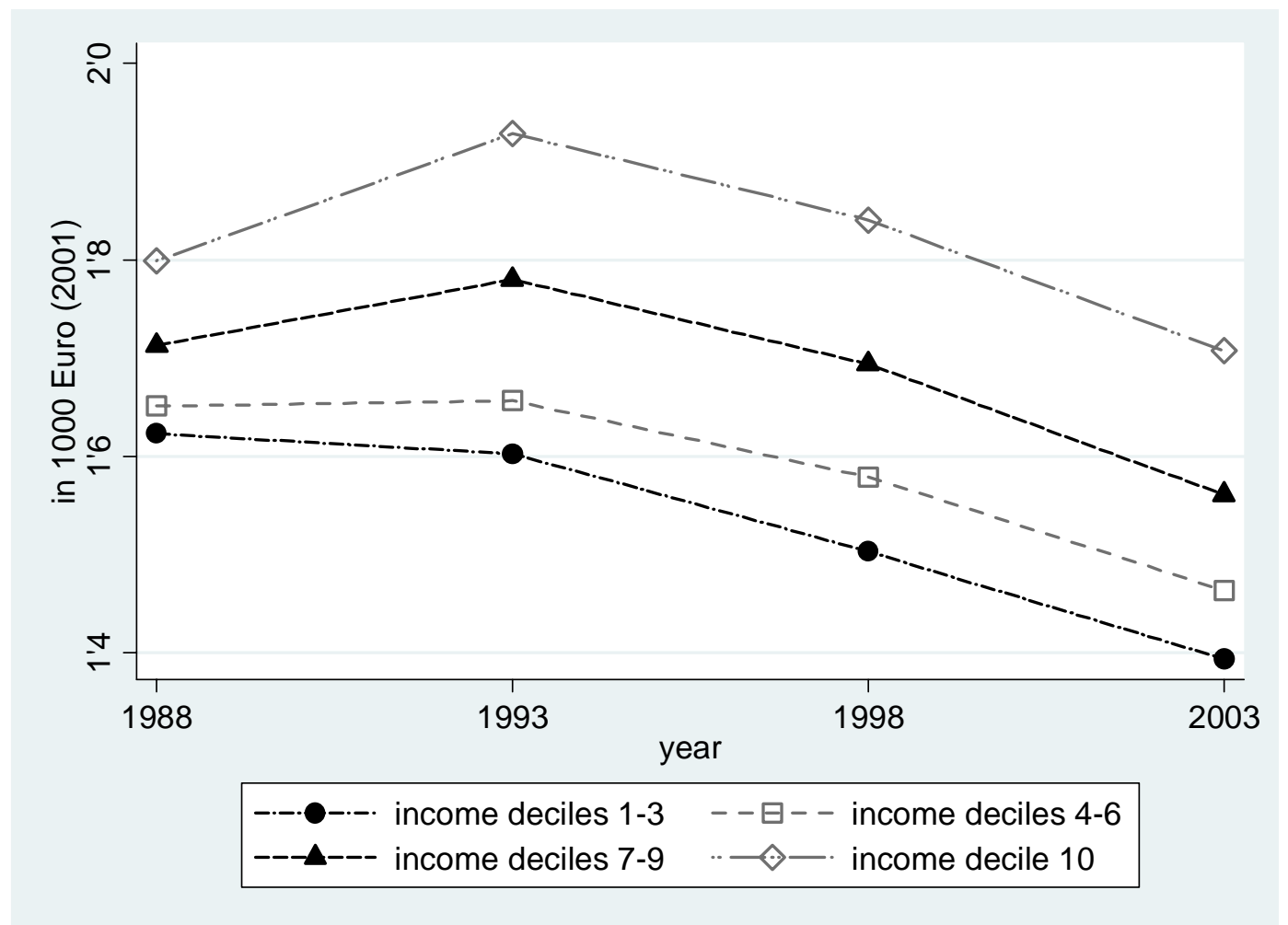

Source: own calculations based on the EVS 1988-2003 


\section{Discussion Paper Series}

Mannheim Research Institute for the Economics of Aging Universität Mannheim

To order copies, please direct your request to the author of the title in question.

\begin{tabular}{|c|c|c|c|}
\hline Nr. & Autoren & Titel & Jahr \\
\hline $152-07$ & $\begin{array}{l}\text { Karsten Hank } \\
\text { Stephanie Stuck }\end{array}$ & $\begin{array}{l}\text { Gesellschaftliche Determinanten produktiven } \\
\text { Alterns in Europa }\end{array}$ & 07 \\
\hline $153-07$ & $\begin{array}{l}\text { Axel Börsch-Supan } \\
\text { Christina B. Wilke }\end{array}$ & $\begin{array}{l}\text { Szenarien zur mittel- und langfristigen } \\
\text { Entwicklung der Anzahl der Erwerbspersonen } \\
\text { und der Erwerbstätigen in Deutschland }\end{array}$ & 07 \\
\hline $154-07$ & $\begin{array}{l}\text { Alexander Ludwig, } \\
\text { Alexander Zimper }\end{array}$ & $\begin{array}{l}\text { A Parsimonious Model of Subjective Life } \\
\text { Expectancy }\end{array}$ & 07 \\
\hline $155-07$ & $\begin{array}{l}\text { Alexander Zimper, } \\
\text { Alexander Ludwig }\end{array}$ & Attitude polarization & 07 \\
\hline $156-08$ & $\begin{array}{l}\text { Florian Heiss, } \\
\text { Daniel McFadden, } \\
\text { Joachim Winter }\end{array}$ & $\begin{array}{l}\text { Mind the Gap! Consumer Perceptions and } \\
\text { Choices of Medicare Part D Prescription Drug } \\
\text { Plans }\end{array}$ & 08 \\
\hline $157-08$ & Wolfgang Kuhle & Demography and Equity Premium & 08 \\
\hline $158-08$ & $\begin{array}{l}\text { Axel Börsch-Supan, } \\
\text { Tabea Bucher-Koenen, } \\
\text { Anette Reil-Held, } \\
\text { Christina Wilke }\end{array}$ & $\begin{array}{l}\text { Zum künftigen Stellenwert der ersten Säule im } \\
\text { Gesamtsystem der Alterssicherung }\end{array}$ & 08 \\
\hline $159-08$ & $\begin{array}{l}\text { Tabea Bucher-Koenen, } \\
\text { Christina Benita Wilke }\end{array}$ & $\begin{array}{l}\text { Zur Anhebung der Altersgrenze: Eine Simulation } \\
\text { der langfristigen Auswirkungen auf die gesetz- } \\
\text { liche Rentenversicherung bei unterschiedlichem } \\
\text { Renteneintrittsverhalten }\end{array}$ & 08 \\
\hline $160-08$ & Mathias Sommer & $\begin{array}{l}\text { Imputation and Harmonisation of Income, } \\
\text { Consumption, Savings and Wealth Data from } \\
\text { the German Income and Expenditure Survey }\end{array}$ & 08 \\
\hline $161-08$ & Karsten Hank & Generationenbeziehungen im alternden Europa & 08 \\
\hline $162-08$ & $\begin{array}{l}\text { Axel Börsch-Supan, } \\
\text { Karsten Hank, } \\
\text { Hendrik Jürges, } \\
\text { Mathis Schröder } \\
\end{array}$ & $\begin{array}{l}\text { Longitudinal Data Collection in Continental } \\
\text { Europe: Experiences from the Survey of Health, } \\
\text { Ageing and Retirement in (SHARE) }\end{array}$ & 08 \\
\hline $163-08$ & Martin Salm & Job loss does not cause ill health & 08 \\
\hline $164-08$ & $\begin{array}{l}\text { Martin Salm, Daniel } \\
\text { Schunk }\end{array}$ & $\begin{array}{l}\text { The role of childhood health for the inter- } \\
\text { generational transmission of human capital: } \\
\text { Evidence from administrative data }\end{array}$ & 08 \\
\hline
\end{tabular}

